\title{
Data assimilation of radar reflectivity volumes in a LETKF scheme
}

\author{
Thomas Gastaldo $^{1,2}$, Virginia Poli ${ }^{1}$, Chiara Marsigli ${ }^{1, a}$, Pier Paolo Alberoni ${ }^{1}$, and Tiziana Paccagnella ${ }^{1}$ \\ ${ }^{1}$ Arpae Emilia-Romagna Hydro-Meteo-Climate Service, Bologna, Italy \\ ${ }^{2}$ Department of Physics and Astronomy, University of Bologna, Bologna, Italy \\ a now at: Deutscher Wetterdienst, Offenbach, Germany
}

Correspondence: Thomas Gastaldo (thomas.gastaldo2@unibo.it)

Received: 16 April 2018 - Discussion started: 26 April 2018

Revised: 1 October 2018 - Accepted: 22 October 2018 - Published: 7 November 2018

\begin{abstract}
Quantitative precipitation forecast (QPF) is still a challenge for numerical weather prediction (NWP), despite the continuous improvement of models and data assimilation systems. In this regard, the assimilation of radar reflectivity volumes should be beneficial, since the accuracy of analysis is the element that most affects short-term QPFs. Up to now, few attempts have been made to assimilate these observations in an operational set-up, due to the large amount of computational resources needed and due to several open issues, like the rise of imbalances in the analyses and the estimation of the observational error. In this work, we evaluate the impact of the assimilation of radar reflectivity volumes employing a local ensemble transform Kalman filter (LETKF), implemented for the convection-permitting model of the COnsortium for Small-scale MOdelling (COSMO). A 4-day test case on February 2017 is considered and the verification of QPFs is performed using the fractions skill score (FSS) and the SAL technique, an object-based method which allows one to decompose the error in precipitation fields in terms of structure $(S)$, amplitude $(A)$ and location $(L)$. Results obtained assimilating both conventional data and radar reflectivity volumes are compared to those of the operational system of the Hydro-Meteo-Climate Service of the EmiliaRomagna Region (Arpae-SIMC), in which only conventional observations are employed and latent heat nudging (LHN) is applied using surface rainfall intensity (SRI) estimated from the Italian radar network data. The impact of assimilating reflectivity volumes using LETKF in combination or not with LHN is assessed. Furthermore, some sensitivity tests are performed to evaluate the effects of the length of the assimilation window and of the reflectivity observational error (roe). Moreover, balance issues are assessed in terms of kinetic energy spectra and providing some examples of how these af-
\end{abstract}

fect prognostic fields. Results show that the assimilation of reflectivity volumes has a positive impact on QPF accuracy in the first few hours of forecast, both when it is combined with LHN or not. The improvement is further slightly enhanced when only observations collected close to the analysis time are assimilated, while the shortening of cycle length worsens QPF accuracy. Finally, the employment of too small a value of roe introduces imbalances into the analyses, resulting in a severe degradation of forecast accuracy, especially when very short assimilation cycles are used.

\section{Introduction}

Numerical weather prediction (NWP) models are widely used in meteorological centers to produce forecasts of the state of the atmosphere. In particular, they play a key role in the forecast of precipitation (Cuo et al., 2011), which arouses great interest due to the many applications in which it is involved, from the issue of severe weather warnings to decision making in several branches of agriculture, industry and transportation. Therefore, an accurate quantitative precipitation forecast (QPF) is of great value for society and economic activities.

In recent years, the increase in available computing resources has allowed one to increment NWP spatial resolution and to improve the accuracy of parametrization schemes, enabling the development of convection-permitting models (Clark et al., 2016). Despite that, QPF is still a challenge since it is affected by uncertainties in timing, location and intensity (Cuo et al., 2011; Röpnack et al., 2013). These errors arise partly from the chaotic behaviour of the atmosphere and from shortcomings in the model physics (Berner et al., 
2015), but the main factor which affects the quality of QPF, especially in the short range $(3-12 \mathrm{~h})$, is the accuracy of initial conditions (Dixon et al., 2009; Clark et al., 2016).

The initial condition (analysis) is generally produced by a data assimilation procedure which combines model state (background or first guess) and observations to provide the best possible estimate of the actual state of the atmosphere at a given time. In the last decades, different assimilation schemes have been proposed and implemented operationally in meteorological centres around the world (Bannister, 2016). They can be divided into different families: those based on a variational approach, like threedimensional variational data assimilation (3D-Var; Courtier et al., 1998) and four-dimensional variational data assimilation (4D-Var; Buehner et al., 2010b), those based on the ensemble Kalman filter (EnKF: Evensen, 1994; Houtekamer and Mitchell, 1998) and those based on the particle filter (PF; see van Leeuwen, 2009 for a review). At the convective scale, EnKF methods seem to be preferable to variational schemes (Schraff et al., 2016). In fact, they determine explicitly the background error covariance, which is highly flowdependent at the convective scale. Furthermore, in a variational scheme it is not straightforward to update any variable of a NWP model since an explicit linear and adjoint relation to the control vector of prognostic variables is needed. These problems can be partly addressed by employing hybrid EnKF-variational techniques (like Wang et al., 2008; Gustafsson and Bojarova, 2014), but these approaches have mostly been applied to larger-scale NWP. A more preferable option would be to employ a PF, which is also considered to be the most promising technique to deal with the non-linear and non-Gaussian characters of dynamics and error statistics (Yano et al., 2018). Unfortunately, despite the efforts to overcome the dimensionality challenges of this assimilation technique (e.g. Poterjoy, 2016), PF is still not feasible for operational applications. Returning to EnKF methods, several variants have been suggested (for a survey, refer to Meng and Zhang, 2011), and one of the most popular is the local ensemble transform Kalman filter (LETKF) proposed by Hunt et al. (2007). It is used operationally in several meteorological centres like at COMET (Bonavita et al., 2010), at MeteoSwiss employing the version of the scheme developed for the COSMO consortium (Schraff et al., 2016) and for research purposes at both the Japan Meteorological Agency (JMA; Miyoshi et al., 2010) and at the European Centre for Medium-Range Weather Forecasts (ECMWF; Hamrud et al., 2015).

The quality of the analysis is determined not only by the data assimilation scheme employed, but also by the quality and number of observations that can be assimilated. With this aim, the assimilation of radar observations can be very beneficial, since they are highly dense in space (both horizontally and vertically) and in time. Up to now, several attempts have been made to improve the quality of analyses and subsequently the accuracy of QPFs by assimilat- ing rainfall data estimated from radar reflectivity observations (Jones and Macpherson, 2006; Leuenberger and Rossa, 2007; Sokol, 2009; Davolio et al., 2017). Conversely, only a few attempts have been made to directly assimilate reflectivity volumes in a convection-permitting model employing EnKF techniques (e.g. Snyder and Zhang, 2003), especially in an operational framework (e.g. Bick et al., 2016). Despite some promising results, many issues affect the assimilation of reflectivity volumes at high spatial resolution, and several aspects need to be further investigated.

First of all, the length of the assimilation window, which is one of the key aspects of any data assimilation system, has to be examined. In EnKF methods, a short window would be desirable to avoid dynamical features leaving the area where computed localized increments are significant (Buehner et al., 2010a) and to better preserve the Gaussianity of the ensemble which can be compromised by nonlinearities (Ferting et al., 2007). On the other hand, too short a window would lead to an increase in imbalances in the analysis, since the model has no time to filter spurious gravity waves, introduced at each initialization, through the forecast step of the assimilation cycle. When reflectivity volumes are assimilated, the window length becomes even more crucial since these observations allow one to catch small-scale features of the atmosphere (Houtekamer and Zhang, 2016). In order to exploit the high temporal frequency of these data, which is essential to properly characterize fast developing and moving precipitation systems, it seems reasonable to employ short windows to assimilate, in each cycle, only observations collected very close to the analysis time. Furthermore, the choice of a short window is encouraged by the use of short localization scales, which has to be employed since small-scale features are observed. Conversely, the large number of radar observations enhances the imbalance issue and, therefore, the imbalances generated in the model by each initialization should be checked and kept under control.

Another important issue is how to determine the observational error for radar reflectivities. As for any other observation, this is influenced by three different sources: instrumental errors, representativity errors and observation operator errors (Janjić et al., 2017). Since none of these are known, the choice of its value is not straightforward and can be estimated only in a statistical sense. Considering the amount of radar data, a correct estimation of the observational error is crucial, since even a small departure from the correct value can have a large impact on the quality of the analyses. Moreover, it should be taken into account that the use of the radar data is highly dependent on the observation operator adopted, and its biases should also be studied and ideally removed. Finally, a further challenge is the estimation of the observational error correlation, especially when dealing with radar data assimilation, due to the high density of this type of observation.

At Arpae-SIMC, the Hydro-Meteo-Climate Service of the Emilia-Romagna Region, in Italy, a LETKF scheme is used 
to provide the initial conditions to the convection-permitting components of the operational modelling chain, consisting of one deterministic run and one ensemble system, both at $2.2 \mathrm{~km}$ horizontal resolution. Currently, only conventional data are assimilated through the LETKF scheme, and latent heat nudging (LHN; Stephan et al., 2008) is performed using rainfall intensity estimated from the Italian radar network data. The purpose of this paper is to present the first results obtained when reflectivity volumes are also assimilated using the LETKF scheme. In particular, the impact of assimilating reflectivity volumes in combination or not with LHN is evaluated. Furthermore, the sensitivity of the obtained analysis to two important characteristics of the assimilation cycle is studied: the length of each cycle and the observational error attributed to the radar reflectivities.

This paper is organized as follows. In Sect. 2 the model and the data assimilation system are described, as well as the observations employed. Furthermore, the operational setup implemented at Arpae is reported in conjunction with the set-up of the experiments performed in this study. In Sect. 3 the verification methods are explained. In Sect. 4 results are shown and discussed. In Sect. 5 some conclusions are drawn.

\section{Data, model and methodology}

\subsection{The COSMO model}

The COSMO model (Baldauf et al., 2011) is a nonhydrostatic limited-area model developed by the multinational COnsortium for Small-scale MOdelling (COSMO) and it is designed for both operational NWP and several research applications. It is based on the primitive equations describing compressible flows in a moist atmosphere and the continuity equation is replaced by a prognostic equation for the pressure perturbation (deviation from a reference state). The prognostic variables involved in these equations are the three-dimensional wind vector, temperature, pressure perturbation, turbulent kinetic energy (TKE) and specific amount of water vapour, cloud water, cloud ice, rain, snow and graupel.

In the present study, the COSMO model is run at $2.2 \mathrm{~km}$ horizontal resolution over a domain covering Italy and part of the neighbouring countries (Fig. 1) and employing 65 terrainfollowing hybrid layers. The model top is at $22 \mathrm{~km}$.

Regarding set-up and parametrizations, deep convection is resolved explicitly, while the shallow convection is parametrized following the non-precipitating part of the Tiedtke scheme (Tiedtke, 1989). Cloud formation and decay is controlled by a Lin-type one-moment bulk microphysics scheme which includes all the prognostic microphysical species (Lin et al., 1983; Seifert and Beheng, 2001). The turbulent parametrization is based on a TKE equation with a closure at level 2.5, according to Raschendorfer (2001). Radiative effects are described by the $\delta$-two-stream radia-

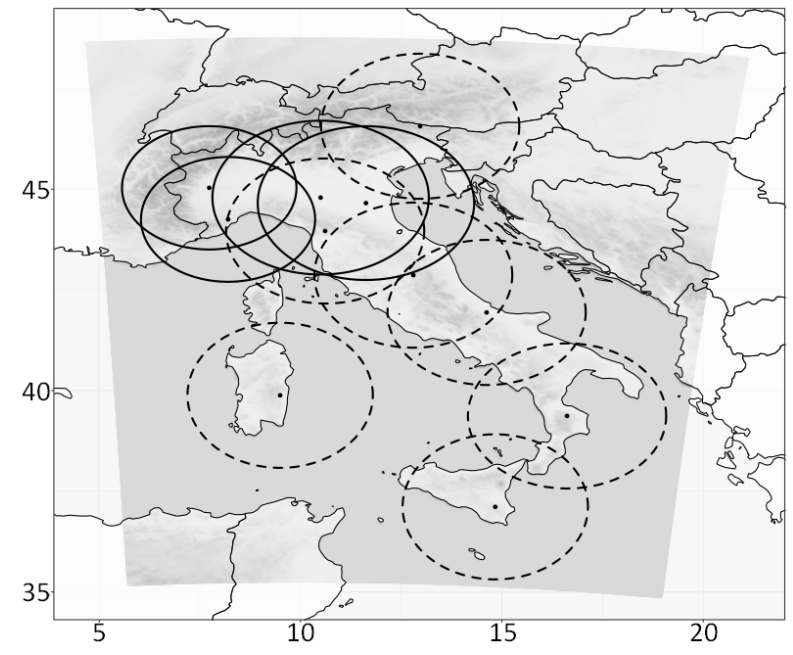

Figure 1. Integration domain (greyscale) of the COSMO model employed in this study with the Italian radar network overlapped. For each radar the approximate coverage area is shown with a dashed line if the radar system contributes only to the SRI composite employed in LHN and with a solid line if it is used also to directly assimilate reflectivity volumes through KENDA.

tion scheme of Ritter and Geleyn (1992) for short-wave and long-wave fluxes. Finally, the lower boundary conditions at the ground are provided by multi-layer soil model TERRA (Doms et al., 2011).

\subsection{The KENDA system}

The KENDA system (Schraff et al., 2016) implements for the COSMO model the LETKF scheme described by Hunt et al. (2007). In this implementation, the method is fully four-dimensional; that is, all observations collected during the assimilation window contribute to determining the analysis and the related model equivalents are computed using the prognostic variables at the proper observation time. To avoid spurious long-distance correlations in the background error covariance matrix, analyses are performed independently for each model grid point taking into account only nearby observations (observation localization). Observations are weighted according to their distance from the grid point considered using the Gaspari-Cohn correlation function (Gaspari and Cohn, 1999). In the present work, two different values of the Gaspari-Cohn localization length scale are employed for conventional and radar observations: $80 \mathrm{~km}$ for the former, $16 \mathrm{~km}$ for the latter (as done by Bick et al., 2016).

The limited size of the ensemble, combined with the assumption of a perfect model made in the LETKF scheme, leads to an underestimation of the background and analysis variances (e.g. Anderson, 2009) and, as a consequence, the quality of analyses is negatively affected. To address this issue, KENDA provides some techniques to enlarge the spread of the ensemble (for a complete description of each of them, 
refer to Schraff et al., 2016). Here, multiplicative covariance inflation (Anderson and Anderson, 1999) and the relaxation to prior perturbation (RTPP; Zhang et al., 2004) are employed. The former consists in inflating the analysis error covariance by a factor $\rho$ greater than 1 which is estimated following Houtekamer et al. (2005). The latter lies on the relaxation of the analysis ensemble perturbations $\boldsymbol{x}_{i}^{\mathrm{a}}-\overline{\boldsymbol{x}}^{\mathrm{a}}$ (where $\boldsymbol{x}_{i}^{\mathrm{a}}$ is the analysis for the $i$ th member and $\overline{\boldsymbol{x}}^{\mathrm{a}}$ is the analysis ensemble mean) towards the background ensemble perturbations $\boldsymbol{x}_{i}^{\mathrm{b}}-\overline{\boldsymbol{x}}^{\mathrm{b}}$, that is,

$\boldsymbol{x}_{i, \text { new }}^{\mathrm{a}}-\overline{\boldsymbol{x}}^{\mathrm{a}}=(1-\alpha)\left(\boldsymbol{x}_{i}^{\mathrm{a}}-\overline{\boldsymbol{x}}^{\mathrm{a}}\right)+\alpha\left(\boldsymbol{x}_{i}^{\mathrm{b}}-\overline{\boldsymbol{x}}^{\mathrm{b}}\right)$,

where $\alpha_{p}=0.75$ (see also Harnisch and Keil, 2015). Another approach provided by KENDA to account for model error is the additive inflation. It consists in adding random noise with mean $\mathbf{0}$ and covariance $\mathbf{Q}$ to the analysis ensemble members, where $\mathbf{Q}$ is the model error covariance matrix (Houtekamer and Mitchell, 2005). Since $\mathbf{Q}$ is not known, it is assumed to be proportional (by a factor smaller than 1) to a static background error covariance B (Mitchell and Houtekamer, 2000). In the present work, additive inflation is not employed.

The KENDA suite also allows one to compute the analysis weights, i.e. the analysis on ensemble space, on a coarsened grid (Yang et al., 2009). After being computed on the coarsened grid, weights are interpolated on the original highresolution grid and then used to compute analysis increments in model space. In this way, the computational cost is decreased without significantly affecting the accuracy of analysis (Yang et al., 2009). In the present study, a coarsening factor equal to 3 is employed.

\subsection{Assimilated data}

KENDA allows the assimilation of both conventional and non-conventional observations.

Conventional observations assimilated in this work include aircraft measurements (AMDAR) of temperature and horizontal wind, surface station measurements (SYNOP) of $10 \mathrm{~m}$ horizontal wind, $2 \mathrm{~m}$ temperature, $2 \mathrm{~m}$ relative humidity and surface pressure, and radiosonde data (TEMP) of temperature, horizontal wind and humidity.

With regards to non-conventional observation, KENDA allows also the assimilation of radar reflectivity volumes and radial winds. Radar data are assimilated through the Efficient Modular VOlume RADar Operator (EMVORADO) expressly designed for the COSMO model. It simulates the radar reflectivity factor and radial velocities processing the COSMO model fields one radar system at a time. Operator characteristics, resolution and the management of noprecipitation information are described in Bick et al. (2016).

Although the operator gives the possibility to assimilate both radial winds and reflectivities, in the present work only reflectivity volumes are assimilated. Reflectivity volumes come from four different radar stations over northern Italy (solid circles in Fig. 1): Bric Della Croce (Piedmont Region), Settepani (Liguria Region), and Gattatico and San Pietro Capofiume (Emilia-Romagna Region). Due to the complex orography of the considered area, radar are placed at very different altitudes and have different acquisition strategies. Observations are acquired every $10 \mathrm{~min}$ for Bric Della Croce radar, every $5 \mathrm{~min}$ for Settepani radar, every $15 \mathrm{~min}$ for San Pietro Capofiume radar and every $15 \mathrm{~min}$ starting from minutes 5 and 10 of each hour for Gattatico radar.

Data have a range resolution of $1 \mathrm{~km}$, while the azimuthal resolution is $1^{\circ}$ for Bric Della Croce and Settepani and 0.9 for San Pietro Capofiume and Gattatico. Before assimilation raw reflectivity is pre-processed, taking into account nonmeteorological echoes, beam blocking and attenuation to improve the quality of data. In particular, it is important to eliminate the clutter signal that would affect the analysis retrieval, introducing spurious observations. However, due to the fact that volumes from single radars undergo different pre-processing, it is not possible to define a homogeneous quality criterion. For this reason, all data in the volume that are not rejected from the pre-processing step are supposed to have the same quality and are used in the assimilation cycle.

The high temporal and spatial density of observations is valuable for estimating the initial state of numerical weather forecast. This allows one to gather a lot of information on the real state of the atmosphere, but it determines an increase in analysis computational cost, in data transfer time and in memory disk occupation. Moreover, a spatial and/or temporal high density violates the assumption made in many data assimilation schemes: the non-correlation of observational errors. To reduce the total amount of data and to extract the essential content of information, the superobbing technique is chosen (Michelson, 2003). In this way, reflectivities over a defined area are combined through a weighted mean into one single observation representative of the desired greater spatial scale. As in Bick et al. (2016), the horizontal resolution chosen in this work for the superobbing is equal to $10 \mathrm{~km}$. Furthermore, before performing superobbing on the observed and simulated fields, a threshold of $5 \mathrm{dBZ}$ is applied to both fields in order to avoid large innovations associated with non-precipitating signals leading to large analysis increments without physical relevance.

To evaluate the observational error associated with reflectivity volumes, a diagnostic based on statistical averages of observations-minus-background and observations-minusanalysis residuals, as described in Desroziers et al. (2005), is used. Employing all radar data available during the test case, a reflectivity observational error (roe) equal to $5 \mathrm{dBZ}$ is estimated, as found also by Tong and Xue (2005).

Finally, fields of surface rainfall intensity (SRI) are also assimilated in each member of the assimilation ensemble using a latent heat nudging scheme. SRI data come from the composite of the Italian radar network (all circles in Fig. 1) and are distributed by the National Department of Civil Protection. These data have a temporal resolution of $10 \mathrm{~min}$ and 
a spatial resolution of $1 \mathrm{~km}$, but before the assimilation they are interpolated at the model resolution. Data coming from each station undergo a quality control that removes those with low quality. The quality depends on different factors such as ground clutter, beam blocking, range distance, vertical variability and attenuation as described in Rinollo et al. (2013). The composite is then obtained as a weighted average of surface rain rates from single radar stations, where weights are represented by quality. These fields are assimilated through the LHN scheme, based on the assumption that the latent heat, integrated along the vertical column, is approximately proportional to the observed precipitation. The scheme, which is applied continuously during the integration of the model, acts in rescaling temperature profiles with an adjustment of the humidity field according to the ratio between observed and modelled rain rates. LHN has been gainfully employed in different frameworks, including forecasts over complex terrain (Leuenberger and Rossa, 2004; Leuenberger and Rossa, 2007). Our hypothesis is that, in the KENDA framework, LHN allows one to have the model first guess closer to the observed atmospheric state, improving the analysis quality. For this reason, in all experiments (except one) presented here, LHN is applied together to the direct assimilation of reflectivity volumes through KENDA.

\subsection{Operational set-up}

The KENDA system is implemented operationally at Arpae using an ensemble of 20 members plus a deterministic run, which is obtained by applying the Kalman gain matrix for the ensemble mean to the innovations of the deterministic run itself. In principle, ensemble mean analyses can be deployed to initialize the deterministic forecasts, but this would lead to some inaccuracies since the mean of a non-Gaussian ensemble is generally not in balance (Schraff et al., 2016). For this reason the deterministic branch is added to the system, which differs from the ensemble ones only due to boundary conditions. The ensemble members use lateral boundary conditions provided every $3 \mathrm{~h}$ at a $10 \mathrm{~km}$ horizontal resolution by the ensemble of the data assimilation system of the Centro Operativo per la Meteorologia (COMet), based on a LETKF scheme (Bonavita et al., 2010). The deterministic run employs hourly boundary conditions provided by a $5 \mathrm{~km}$ version of the COSMO run at Arpae (COSMO-5M), whose domain covers a large part of the Mediterranean basin and surrounding countries.

At Arpae, in the operational set-up, the COSMO model configuration described in Sect. 2.1 is adopted for all 21 members. At present, in the operational chain only conventional observations are assimilated and LHN is performed on each member of the ensemble. The KENDA analyses are used operationally to provide initial conditions to COSMO2I, the $2.2 \mathrm{~km}$ deterministic run initialized twice a day at 00:00 and 12:00 UTC, and to COSMO-2I EPS, an ensem- ble which is run every day at 00:00 UTC for a $48 \mathrm{~h}$ forecast range.

\subsection{Experimental set-up}

In order to evaluate the impact of the assimilation of reflectivity radar volumes, several experiments are performed. Each experiment has the same set-up of the operational chain described in Sect. 2.4 regarding the number of members of the ensemble, boundary conditions and the COSMO model configuration. Therefore, they differ only due to the assimilation set-up. The complete list is provided in Table 1.

In the conv60 and conv60_nolhn experiments only conventional observations are assimilated using KENDA through cycles of $60 \mathrm{~min}$. Moreover, in the former, LHN is performed during the forecast step of each assimilation cycle, replicating completely the operational set-up described in Sect. 2.4. Experiments rad60 and rad60_nolhn are analogous to conv60 and conv60_nolhn but, in addition, radar reflectivity measurements are assimilated through KENDA, using a reflectivity observation error (roe) of $5 \mathrm{dBZ}$. A comparison between conv60 and rad60 or between conv60_nolhn and rad60_nolhn allows an assessment of whether, under the same conditions, the assimilation of reflectivity observations improves the quality of analyses. Furthermore, comparing rad60 to rad60_nolhn, it is possible to evaluate whether the assimilation of reflectivity volumes combined with the LHN provides better results than the assimilation of radar volumes only.

All the other experiments involve the assimilation of both conventional data and reflectivity volumes, in addition to LHN. In order to test the impact of assimilating only observations which are not too far from the analysis time, sensitivity experiments on the duration of the assimilation windows are performed. This is tested by comparing rad60 to experiments rad30 and rad15, which differ from rad60 only for the length of the assimilation window, equal to 30 and $15 \mathrm{~min}$ respectively. An alternative way to assimilate only the most relevant observations is to select in each cycle a subset of data including the closest to the analysis time. In experiment rad60_lst 15 an assimilation window of $60 \mathrm{~min}$ is employed, but only the observations (both conventional and radar reflectivities) collected in the last $15 \mathrm{~min}$ of the cycle are taken into account.

Since the estimation of observation error is not straightforward and different techniques can be applied, it is worth evaluating the sensitivity of the assimilation system to this parameter. In addition to the value of $5 \mathrm{dBZ}$ employed in the previous experiments, two other values are selected: 10 or $0.5 \mathrm{dBZ}$. Both of them are tested employing a $60 \mathrm{~min}$ assimilation window (rad60_roe10 and rad60_roe0.5) and using 15 min cycles (rad15_roe10 and rad15_roe0.5).

The experiments described above are carried out over a period of almost 4 days from 3 February at 06:00 UTC to 7 February at 00:00 UTC in 2017. During 3 and 4 Febru- 
Table 1. Experimental set-up of each experiment, including the length of the assimilation cycles, the type of observations assimilated, the reflectivity observation error (roe) associated with radar data and any additional feature.

\begin{tabular}{lrlrl}
\hline Trial & $\begin{array}{r}\text { Window } \\
\text { length (min) }\end{array}$ & $\begin{array}{l}\text { Assimilated } \\
\text { obs. }\end{array}$ & $\begin{array}{r}\text { roe } \\
(\mathrm{dBZ})\end{array}$ & Note \\
\hline conv60 & 60 & conv. & - & - \\
conv60_nolhn & 60 & conv. & - & No LHN \\
rad60 & 60 & conv. + radar & 5 & - \\
rad60_nolhn & 60 & conv. + radar & 5 & No LHN \\
rad30 & 30 & conv. + radar & 5 & - \\
rad15 & 15 & conv. + radar & 5 & - \\
rad60_1st15 & 60 & conv. + radar & 5 & Use obs. in the last 15 min \\
& & & & of the window \\
rad60_roe10 & 60 & conv. + radar & 10 & - \\
rad60_roe0.5 & 60 & conv. + radar & 0.5 & - \\
rad15_roe10 & 15 & conv. + radar & 10 & - \\
rad15_roe0.5 & 15 & conv. + radar & 0.5 & - \\
\hline
\end{tabular}

ary, middle tropospheric circulation over northern and central Italy was dominated by southwesterly divergent flows associated with the passage of some precipitating systems. On 5 February a trough moved from France to Italy and this caused the formation of new precipitating systems in northern Italy. During 6 February the trough moved slowly from central Italy to the southern part of the country and precipitation systems weakened gradually. For each experiment, analyses of the deterministic member are used to initialize forecasts up to $24 \mathrm{~h}$ every $3 \mathrm{~h}$ from 3 February at 12:00 UTC to 6 February at 06:00 UTC with a total of 22 forecasts.

\section{Verification}

The performance of the experiments described in the previous section is assessed by the verification of precipitation employing three methods: comparison of areal average precipitation, SAL technique and fractions skill score (FSS). The first method is applied only to the precipitation during the assimilation procedure for the deterministic member of the first four experiments in Table 1, while SAL and FSS are used to evaluate the QPF accuracy of the 22 forecasts initialized for each experiment.

\subsection{Areal average precipitation}

The method consists in comparing spatially averaged model precipitation to the average precipitation observed by rain gauges over the same area. In order to have comparable samples, model precipitation is first interpolated on station locations by selecting the value at the nearest grid point. The raingauge stations employed for this verification method (nearly 1500) are the black dots in the dark grey region in Fig. 2. This area is chosen to cover approximately the domain where reflectivity volumes are assimilated. Both model and raingauge precipitation are accumulated in $3 \mathrm{~h}$ steps. Since this

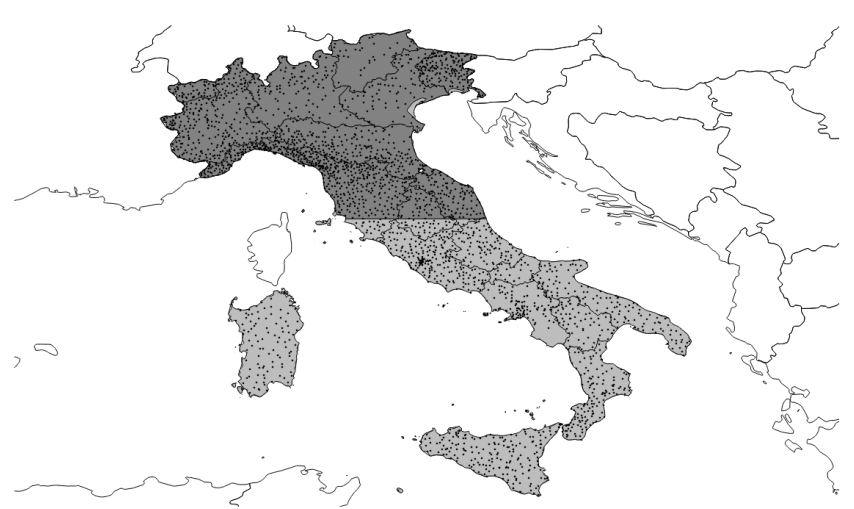

Figure 2. Verification domains employed to perform SAL (dark grey area) and FSS (union of dark grey and light grey areas). The rain gauges (black dots) are used to correct precipitation estimated from the Italian radar network. Furthermore, rain gauges over the black grey domain are employed for the verification of areal average precipitation during the assimilation procedure.

method is used for the verification during the assimilation procedure and the duration of each assimilation cycle, for the experiments considered, is $1 \mathrm{~h}$, model hourly precipitation is accumulated in order to obtain the 3-hourly precipitation. To summarize the results, the correspondence between model and observations is evaluated in terms of root mean square error (RMSE).

\subsection{SAL}

The SAL metrics (Wernli et al., 2008) is an object-based verification score which allows one to overcome the limitations of traditional scores for convection-permitting models, like the double-penalty problem (Rossa et al., 2008). The detection of individual objects in the accumulated precipitation fields is achieved by considering continuous areas of grid 
points exceeding a selected threshold. Comparing objects from observed and forecast fields, SAL provides information about the structure $S$, the amplitude $A$ and the location $L$ errors of QPF. A perfect match between forecast and observations would lead to $S=A=L=0$; the more the values differ from 0 , the greater the disagreement between model and observations. More in detail, too sharp/flat (broad/small) a structure of forecast precipitation compared to observations is associated with positive (negative) values of $S$; an overestimation (underestimation) of average rainfall over the domain is associated with positive (negative) values of $A$; a misplacement of precipitating systems leads to positive values of $L$. Note that $L$ can range between 0 and 2, and $S$ and $A$ between -2 and 2 .

Observations employed to perform SAL are hourly accumulated precipitation estimated from the Italian radar network and corrected using rain-gauge data. The radar-raingauge adjustment, adapted for a radar composite, derives from the method described in Koistinen and Puhakka (1981). The original method comprises two terms: a range dependency adjustment and a spatially varying adjustment. In our case, only the second term is taken into account due to the fact that, in overlapping areas of the composite, rainfall estimation is obtained by combining data from different radars and, therefore, the original information on the range distance from the radar is lost. The correction is based on a weighted mean of the ratio between rain gauges and estimated radar rainfall amount calculated over the station locations. Weights are a function of the distance of the grid point from the station and of a filtering parameter calculated as the mean spacing between five observations. Then a smoothing factor is applied to the correction.

The verification area, shown in dark grey in Fig. 2, is the same as for the areal average precipitation. In this case, the rain gauges inside it are employed to correct the rainfall estimation from the radar network. As mentioned before, this area covers approximately the domain where reflectivity volumes are assimilated. The choice of a larger domain would not be feasible. In Wernli et al. (2009) it is recommended to use an area not larger than $500 \times 500 \mathrm{~km}^{2}$ since, otherwise, the domain may include different meteorological systems, making the interpretation of results problematic. In fact, if the domain contains strongly differing meteorological systems, then results obtained using the SAL technique may not be representative of the weakest one.

\subsection{FSS}

The fractions skill score is a verification method introduced by Roberts and Lean (2008) based on the neighbourhood approach and applied to fractional coverage, that is, the fraction of grid points exceeding a threshold. The score consists in comparing forecast and observed fractional coverage over a squared box (neighbourhoods) and it ranges between 0 (completely wrong forecast) and 1 (perfect forecast). Therefore, a perfect match between model and observations is obtained when the two fields have the same frequency of events in each box. In this way, the method implicitly acknowledges that the actual resolution of a model is larger than the grid resolution and, at the same time, that observations may also contain random error at the model grid scale. Like SAL, this approach allows one to overcome the limitation of traditional grid-point-based scores. Furthermore, it can be applied over a domain larger than that employed for SAL since it is based on dichotomy events instead of being based on the amount of precipitation. For this reason, in this work FSS is applied over the whole country of Italy (union of dark grey and light grey domains in Fig. 2) considering boxes of $0.2^{\circ}$ in both latitude and longitude and, as for SAL, observations consist in hourly accumulated precipitation estimated from the Italian radar network corrected using rain-gauge data (all black dots in Fig. 2).

\section{Results}

\subsection{Impact of assimilating the radar reflectivities}

A preliminary assessment of the impact of assimilating radar reflectivity volumes with the KENDA system is provided by comparing two pairs of experiments: conv60_nolhn with rad60_nolhn and conv60 with rad60. In the experiment named conv60_nolhn only conventional observations are assimilated, while in the rad60_nolhn experiment both conventional and radar reflectivity volumes are employed. The same dichotomy is preserved in the second pair of experiments but, in this case, LHN of SRI data is performed additionally in both conv60 and rad60.

The areal average of 3-hourly precipitation during the assimilation procedure is displayed in Fig. 3, employing precipitation recorded by rain gauges (black line) as an independent reference observation. Comparing rad60_nolhn (solid orange line) to conv60_nolhn (dashed blue line), the correspondence between forecast and observed precipitation is improved when reflectivity volumes are assimilated in combination with conventional data through KENDA. In fact, the RMSE is reduced from $0.38 \mathrm{~mm}$ of conv60_nolhn to $0.26 \mathrm{~mm}$ of the rad60_nolhn experiment. The same conclusion holds when the assimilation through KENDA is combined with LHN: the RMSE is reduced from $0.37 \mathrm{~mm}$ of conv60 (dashed red line) to $0.29 \mathrm{~mm}$ of rad60 (solid green line; this colour will be used from here onwards to identify uniquely this experiment). Note that the LHN does not substantially affect the overall agreement between forecast and observed precipitation when it is combined with the assimilation of only conventional data (RMSE equal to $0.38 \mathrm{~mm}$ for the conv60_nolhn experiment and $0.37 \mathrm{~mm}$ for conv60) but slightly degrades the correspondence when reflectivity volumes are also employed (RMSE equal to $0.26 \mathrm{~mm}$ for the rad60_nolhn experiment and $0.29 \mathrm{~mm}$ for rad60). 


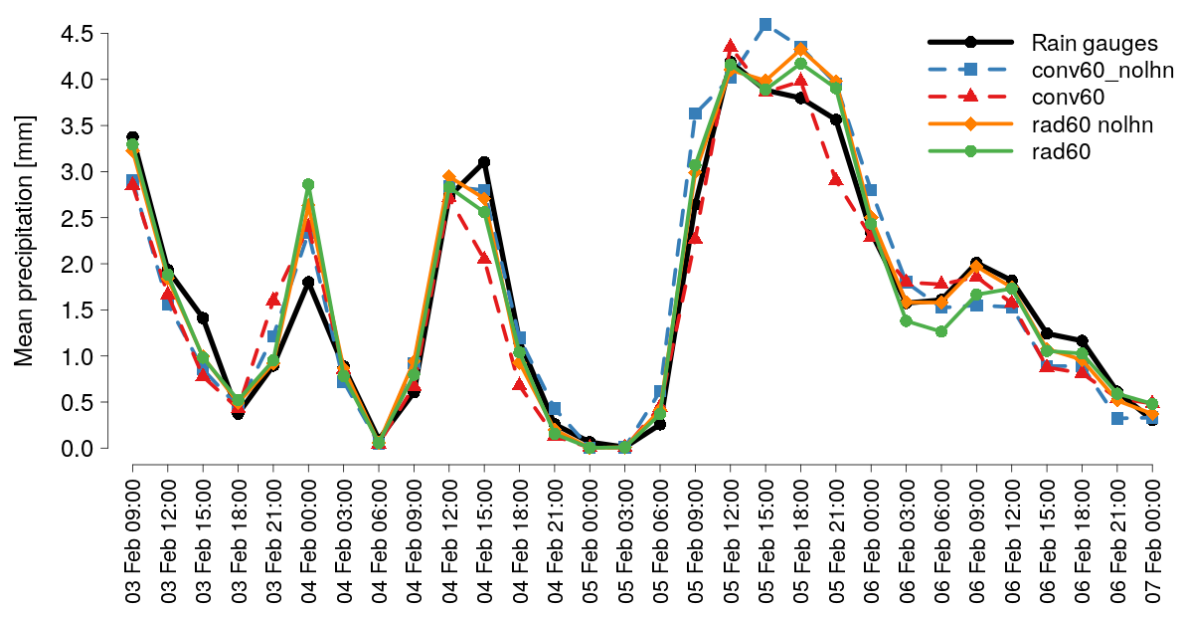

Figure 3. Areal average 3-hourly precipitation for rain gauges (black) in the verification area shown in dark grey in Fig. 2 and for the corresponding model forecast, during the assimilation procedure, relative to experiments conv60_nolhn (dashed blue line), conv60 (dashed red line), rad60_nolhn (solid orange line) and rad60 (solid green line).

Verification of areal average precipitation during the assimilation procedure suggests that the quality of analyses is improved when radar reflectivity volumes are assimilated. To validate this result, the accuracy of QPF for the 22 forecasts initialized for each experiment is evaluated. In order to give an insight into how analysis affects a forecast, hourly forecast precipitation from analyses on 3 February at 12:00 UTC is shown in Fig. 4. Each column represents different lead times, from +1 to $+3 \mathrm{~h}$ going from left to right. The first row is the observed rainfall estimated from radars corrected by rain gauges, that is, the observed field employed for SAL and FSS described in Sect. 3. The shaded yellow area highlights the acquisition domain of the Italian radar network. The other rows are, in order from top to bottom, the forecasts of experiments conv60_nolhn, conv60, rad60_nolhn and rad60. Forecast precipitation of conv60_nolhn is too weak and too spread out, especially at lead time $+2 \mathrm{~h}$, in which large nuclei are forecast west of $12^{\circ} \mathrm{E}$. A significant improvement at $+1 \mathrm{~h}$ is obtained when considering conv60, even if a strong unobserved nucleus is forecast near $45.5^{\circ} \mathrm{N}$ $13.5^{\circ} \mathrm{E}$, while at $+2 \mathrm{~h}$ and especially at $+3 \mathrm{~h}$ the precipitation is completely misplaced. When considering forecasts initialized from rad60_nolhn and rad60, rainfall accuracy at $+1 \mathrm{~h}$ is further enhanced in terms of location. Moreover, a significant improvement of both experiments compared to conv60_nolhn and conv60 can be noticed in location and intensity at lead times +2 and $+3 \mathrm{~h}$. In particular, rad60 is the only one able to forecast nuclei of the correct intensity, with just a slight misplacement error.

For an objective verification of QPF, hourly precipitation of the 22 forecasts initialized from the analyses of each experiment is verified using SAL; to detect rainfall objects, a $1 \mathrm{~mm}$ threshold is set. The verification using a threshold of $3 \mathrm{~mm}$ is also performed but, since results do not differ significantly from those obtained with a $1 \mathrm{~mm}$ threshold, they are not shown here. Following the approach of Davolio et al. (2017), in Fig. 5 the average of the absolute value of each component of SAL is plotted as a function of lead time. Although forecasts are up to $24 \mathrm{~h}$, the verification is shown only for the first $8 \mathrm{~h}$, since after this lead time scores of the different experiments become very close. The average is computed considering only cases in which the observed or forecast rainfall field consists of at least 1000 grid points, which is approximately equal to an area of $50 \times 50 \mathrm{~km}^{2}$. Using the absolute value of the components of SAL, only the magnitude of the error is considered, losing the information on the type of error (e.g. for $A$, an overestimation of forecast precipitation cannot be distinguished from an underestimation). This choice slightly limits the potential of SAL but provides an intuitive picture of the overall performance of each experiment.

Comparing conv60_nolhn to rad60_nolhn, QPF accuracy is slightly improved when forecasts are initialized from analyses obtained by assimilating both conventional data and reflectivity volumes instead of employing only conventional data. In fact, at lead times +1 and $+2 \mathrm{~h}$ values of each component of SAL of rad60_nolhn are smaller than those of conv60_nolhn. An improvement can be noticed also at $+3 \mathrm{~h}$ in the $A$ component, while $S$ and $L$ are substantially unaffected. At $+4 \mathrm{~h} S$ and $A$ are improved, while $L$ is very slightly deteriorated. From $+5 \mathrm{~h}$ onwards, slight improvements and deteriorations alternate in an incoherent manner; therefore, we can conclude that the impact on QPF of using conv60_nolhn or rad60_nolhn analyses is substantially neutral.

The accuracy of QPF obtained by assimilating conventional data is improved at lead times +1 and $+2 \mathrm{~h}$ by activating LHN during the assimilation procedure: all components of SAL for the conv60 experiment are smaller than those of conv60_nolhn. The positive impact of LHN is al- 


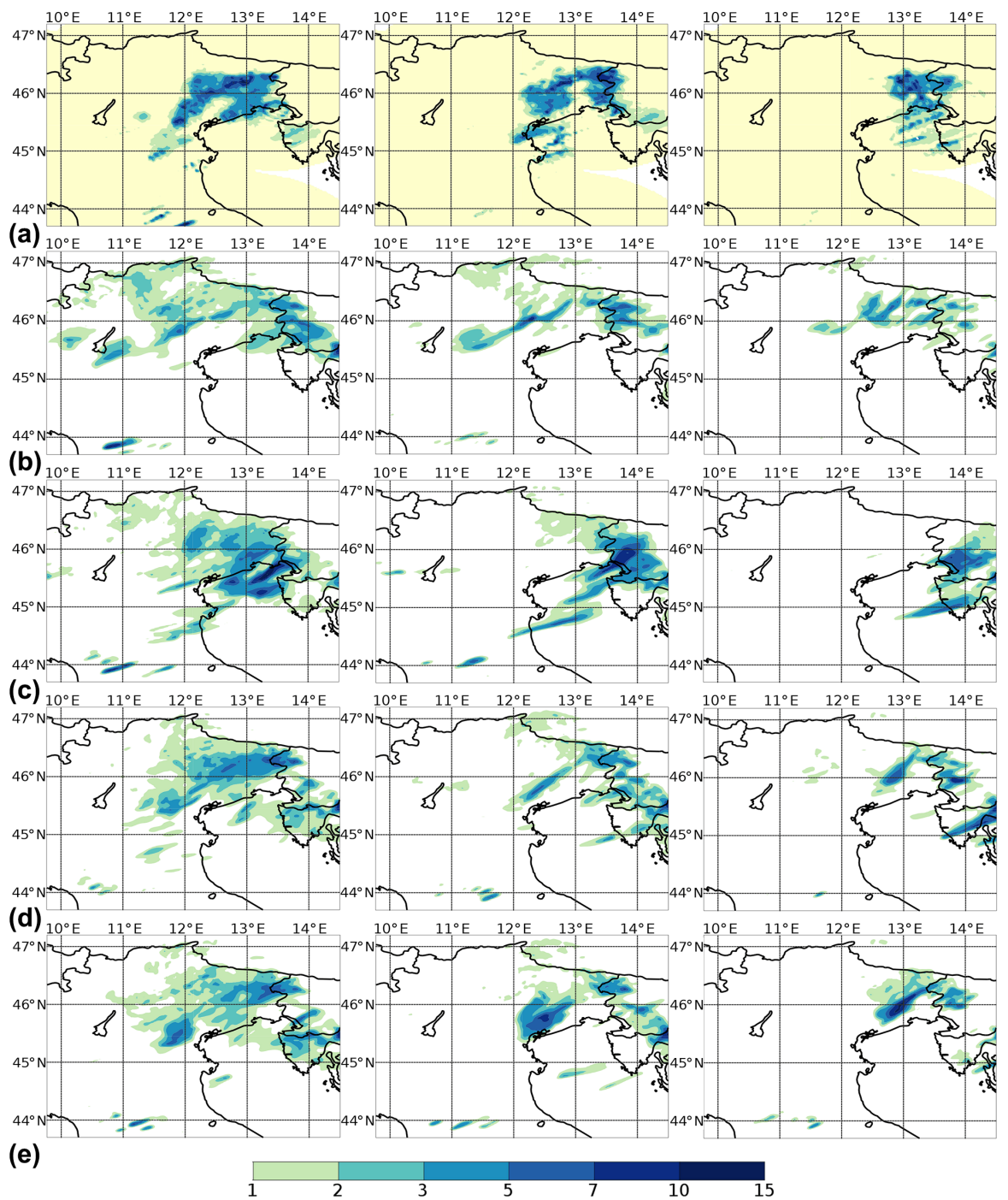

Figure 4. In panel (a), the observed field, consisting of hourly rainfall estimated from radars corrected by rain gauges, is shown for 8 February at 13:00, 14:00 and 15:00 UTC; the shaded yellow area highlights the acquisition domain of the Italian radar network. In the subsequent rows, forecast hourly precipitation of experiments conv60_nolhn (b), conv60 (c), rad60_nolhn (d) and rad60 (e) initialized on 3 February at 12:00 UTC is shown. Each column represents different lead times, from +1 to $+3 \mathrm{~h}$ going from left to right.

ready lost at $+3 \mathrm{~h}$ (in particular, a significant degradation in the $L$ component is observed) but, again, a benefit can be obtained by also assimilating reflectivity volumes. In fact, although at $+1 \mathrm{~h}$ the structure and amplitude errors of rad60 are larger than those of conv60 (while the location error is slightly smaller), from +2 to $+4 \mathrm{~h}$ each component of SAL is smaller, indicating a clear improvement in QPFs accuracy. Again, from $+5 \mathrm{~h}$ onwards, the impact of initializing forecasts from different analyses becomes neutral. Regarding the combined use of LHN and the assimilation of reflectivity volumes through KENDA, at +1 h the $S$ component for rad60 is slightly larger than that of rad60_nolhn, while $A$ and $L$ are almost equal. From +2 to $+4 \mathrm{~h}$ each component of SAL of rad60 is always equal to or slightly smaller than the corresponding one of rad60_nolhn.

Finally, to strengthen the results obtained using SAL over northern Italy, the verification of QPF is extended to the whole country of Italy employing FSS. Results are shown in Fig. 6 for two thresholds: $1 \mathrm{~mm}$ (solid lines) and $5 \mathrm{~mm}$ (dashed lines). Regarding the $1 \mathrm{~mm}$ threshold, a strong improvement in QPF accuracy can be noticed at $+1 \mathrm{~h}$ when reflectivity volumes are assimilated (rad60_nolhn and rad60 experiments). At this lead time also, only the use of LHN (conv60) is able to improve significantly the assimilation of conventional data (conv60_nolhn). At $+2 \mathrm{~h}$ the FSS value of the two experiments in which reflectivities are assimilated is still slightly larger than that of conv60_nolhn, while 


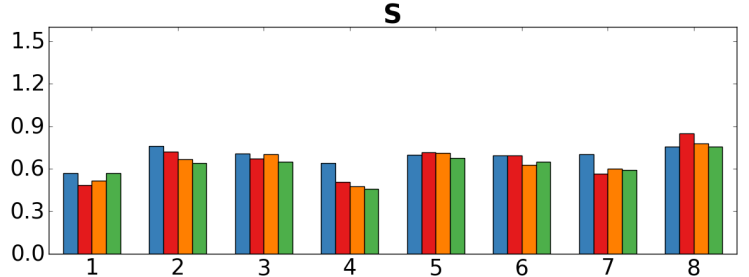

A

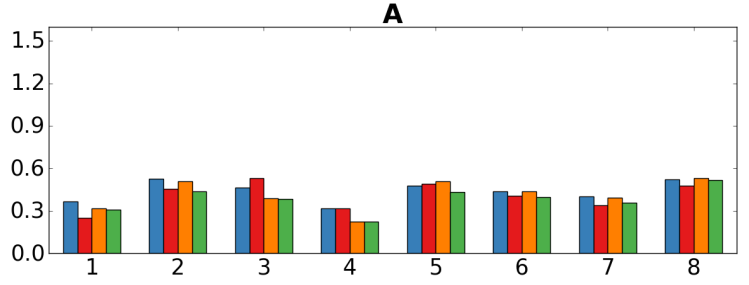

L

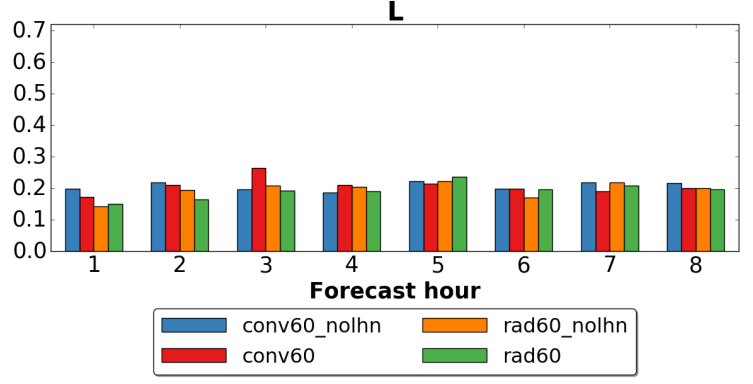

Figure 5. Average of the absolute value of each component of SAL over the 22 forecasts initialized from conv60_nolhn (blue), conv60 (red), rad60_nolhn (orange) and rad60 (green) analyses. Objects are selected using a threshold of $1 \mathrm{~mm}$ in hourly accumulated precipitation fields. Cases in which the observed precipitation field consists of less than 1000 points are not taken into account in the average.

from $+3 \mathrm{~h}$ onwards differences become very small. Regarding conv60, the QPF accuracy strongly worsens between +2 and $+4 \mathrm{~h}$, and it is the worst among the four experiments. Similar conclusions hold when the $5 \mathrm{~mm}$ threshold is considered but, in this case, QPF of experiments in which reflectivity volumes are assimilated outperforms conv60 even at the first hour of forecast. Furthermore, values of FSS of rad60_nolhn are slightly larger than those of rad60 between +2 and $+4 \mathrm{~h}$.

In conclusion, summarizing the verification with SAL and FSS, at lead time $+1 \mathrm{~h}$ the assimilation of both conventional data and reflectivity volumes (rad60 and rad60_nolhn) has a positive impact on QPF accuracy compared to the assimilation of only conventional data (conv60_nolhn). The improvement is seen not only where reflectivities are assimilated (northern Italy), but also over a much larger area (the whole country of Italy). Verification with SAL shows that a slight positive impact over northern Italy holds up to $+4 \mathrm{~h}$, while FSS scores reveal a benefit up to $+2 \mathrm{~h}$ over Italy for both 1 and $5 \mathrm{~mm}$ thresholds. The two experiments in which reflectivity volumes are assimilated do not substantially improve the QPF accuracy at $+1 \mathrm{~h}$ of the experiment in which only conventional data are assimilated in combination with LHN

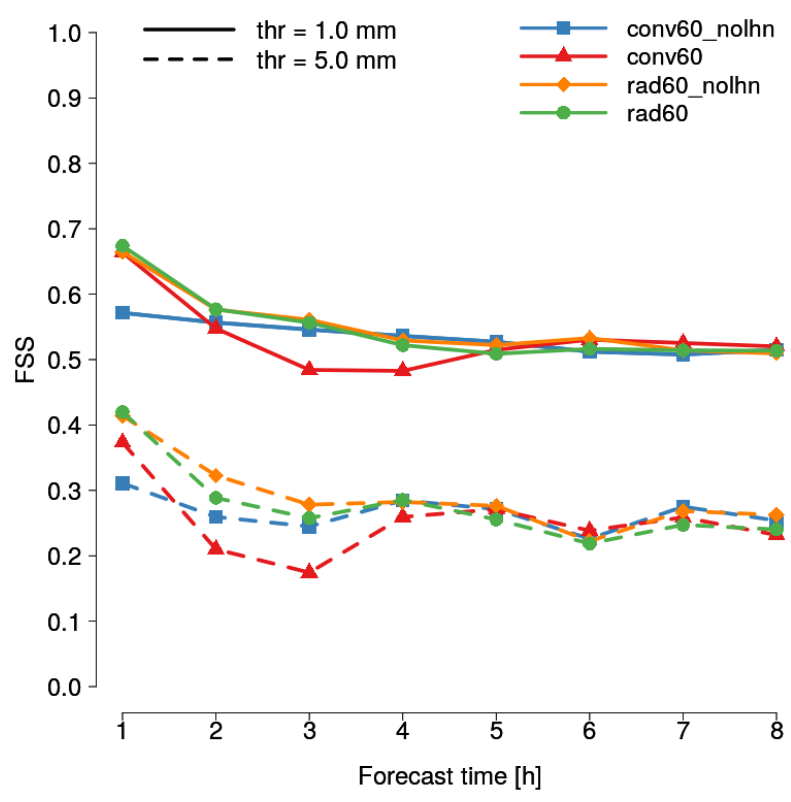

Figure 6. Fractions skill score as a function of lead time for conv60_nolhn (blue), conv60 (red), rad60_nolhn (orange) and rad60 (green). Verification is performed considering hourly precipitation and $1 \mathrm{~mm}$ (solid lines) and $5 \mathrm{~mm}$ (dashed lines) thresholds.

(conv60). However, they remarkably outperform it from +2 to $+4 \mathrm{~h}$, as highlighted by both SAL and FSS. In this case, the positive impact is even enhanced when the $5 \mathrm{~mm}$ threshold is considered.

Finally, regarding the use of LHN combined with the assimilation of reflectivity volumes, SAL shows comparable results between rad60 and rad60_nolhn at $+1 \mathrm{~h}$, while QPF accuracy of rad60 is very slightly enhanced compared to rad60_nolhn between +2 and $+4 \mathrm{~h}$. Verification with FSS does not show significant differences between the two experiments for the $1 \mathrm{~mm}$ threshold, while rad60_nolhn very slightly outperforms rad60 at +2 and $+3 \mathrm{~h}$ for the $5 \mathrm{~mm}$ threshold. Therefore, we can conclude that QPF accuracy is substantially unaffected by assimilating twice information derived from radar. On the basis of this result, even if we recognize that the combined assimilation of reflectivity volumes through KENDA and SRI by LHN may not be a rigorous process from a theoretical point of view, it is decided to keep the LHN for the subsequent experiments. In fact, this choice does not affect negatively the results of the sensitivity tests that are presented in this work and, at the same time, the LHN allows one to use radar-derived information on the state of the atmosphere in the whole country of Italy, despite reflectivity volumes being assimilated, at present, only over northern Italy. 


\subsection{Impact of the length of the assimilation cycles}

To obtain some insights into this topic, assimilation cycles of 15 and $30 \mathrm{~min}$ (respectively rad15 and $\mathrm{rad} 30$ ) are tested and the results are compared to those obtained with the $60 \mathrm{~min}$ window ( $\mathrm{rad60}$ ) discussed in the previous subsection. Furthermore, an experiment in which observations are assimilated only if collected during the last $15 \mathrm{~min}$ of hourly assimilation cycles is performed (rad60_lst15). Accordingly, the total amount of assimilated data is reduced and the increments computed by the LETKF scheme should be more appropriate for computing the analysis, since the observations time is always very close to the analysis time.

In the same way as described in the previous subsection, QPF accuracy of the 22 forecasts initialized for each experiment is verified employing SAL and FSS. Results are shown, respectively, in Figs. 7 and 8 for rad15 (red), rad30 (orange), rad60 (green) and rad60_lst15 (blue). Considering SAL verification, at lead time $+1 \mathrm{~h}$ the shorter the cycle the smaller the error in structure and amplitude; however, the smallest location error among the experiments which differ only for the cycle length is associated with rad30, while rad15 and rad60 are almost equal. Moreover, at lead time $+1 \mathrm{~h}$ QPF of rad60_lst15 is also more accurate than that of rad 60 in each component. Between +2 and $+4 \mathrm{~h}$, both $\mathrm{rad} 15$ and rad30 always have larger errors than rad60, with the only exception of $S$ at $+4 \mathrm{~h}$. In particular, a relevant worsening in the location of rainfall nuclei is observed at $+3 \mathrm{~h}$. Regarding rad60_lst15, the comparison with rad60 in the same forecast range reveals that the differences are always small but, except for $S$ at +2 and $+3 \mathrm{~h}$, rad60 slightly outperforms rad60_lst 15. From lead time $+5 \mathrm{~h}$ onwards, differences among the four experiments become small and the results are mixed.

Extending the verification to the whole country of Italy employing FSS, at +1 h no significant differences can be noticed among the four experiments when the $1 \mathrm{~mm}$ threshold is considered. Between +2 and $+4 \mathrm{~h}$, as observed with SAL verification, the shortening of the assimilation cycle worsens the QPF accuracy. Similarly, the differences between rad60 and rad60_lst 15 are very small but, contrary to what was observed with SAL, in this case the latter very slightly outperforms the former. From $+5 \mathrm{~h}$ onwards, FSS values of all the experiments are almost equal. When the $5 \mathrm{~mm}$ threshold is considered, the comparison between $\mathrm{rad} 15$, rad30 and rad60 leads to the same results as those observed for the $1 \mathrm{~mm}$ threshold, with even more pronounced differences at lead times +2 and $+3 \mathrm{~h}$. Regarding rad60_lst 15 , a significant improvement compared to rad60 is noticed at $+1 \mathrm{~h}$ and a slightly positive impact still holds at the subsequent lead times.

In summary, assimilating observations collected in the last $15 \mathrm{~min}$ of hourly cycles does not affect significantly the QPF accuracy when a $1 \mathrm{~mm}$ threshold is considered: at $+1 \mathrm{~h}$ a slight improvement is observed only over north-
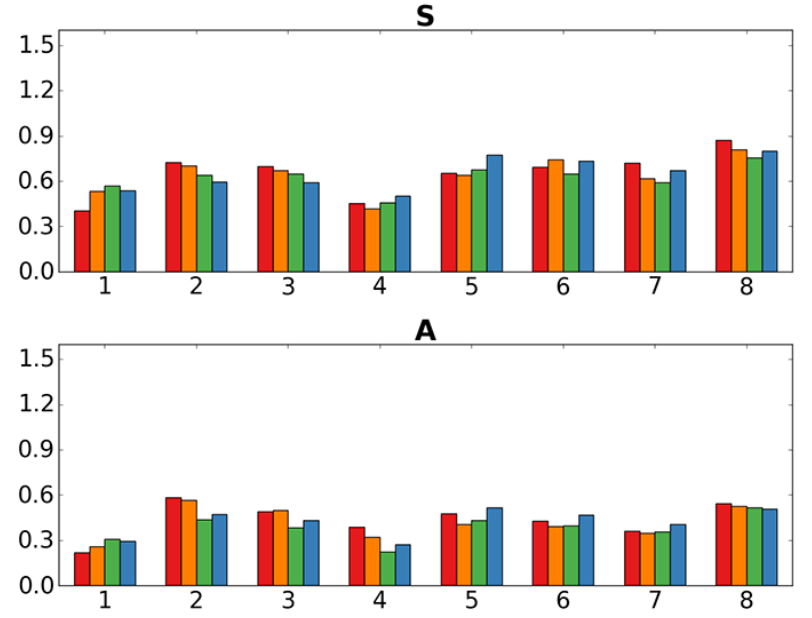

$\mathbf{L}$

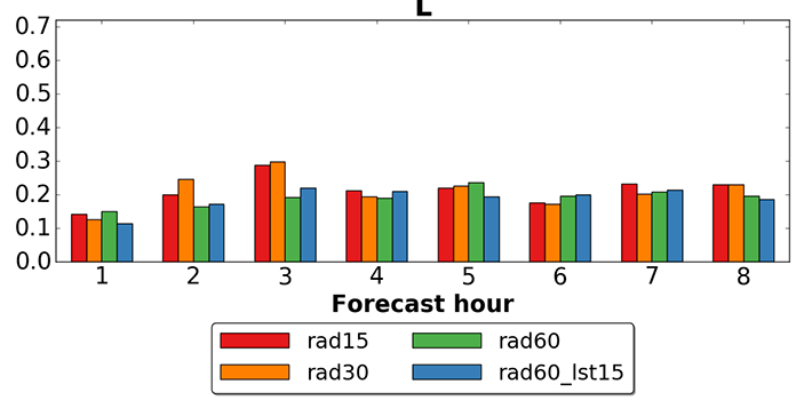

Figure 7. As in Fig. 5 but considering experiments rad15 (red), rad30 (orange), rad60 (green) and rad60_lst15 (blue).

ern Italy, while from $+2 \mathrm{~h}$ onwards the mixed results obtained with FSS and SAL suggest a neutral impact. However, rad60_lst15 slightly outperforms rad60 over the whole country of Italy when the $5 \mathrm{~mm}$ threshold is considered. Regarding the length of assimilation cycles, when it is shortened a slight improvement on QPF accuracy is observed at $+1 \mathrm{~h}$ over northern Italy, but the impact over Italy is neutral. Thereafter, from +2 to $+4 \mathrm{~h}$, a clear worsening is observed both where assimilation is performed and in the rest of Italy. To investigate whether this worsening is due to the imbalance issue, the kinetic energy (KE) spectra of the experiments are computed following the method described in Errico (1985). Curves displayed in Fig. 9 are obtained as an average over the whole assimilation period (from 3 February at 06:00 UTC to 7 February at 00:00 UTC) of KE spectra computed each hour using analysis values of $u, v$ and $w$ over the whole domain. Kinetic energy spectra of rad15 (red) and rad60 (green) are almost overlapping, even at very small wavelengths, indicating that shortening the length of cycles from 60 to $15 \mathrm{~min}$ does not introduce imbalances into the analyses (Skamarock, 2004). Furthermore, both spectra have a $-5 / 3$ dependence on the wavenumber beyond a wavelength of $15-20 \mathrm{~km}$, in agreement with observed spectra at the mesoscale (Nastrom and Gage, 1985). The same considerations also apply to KE spectra of rad30, which is not shown. Therefore, with the 


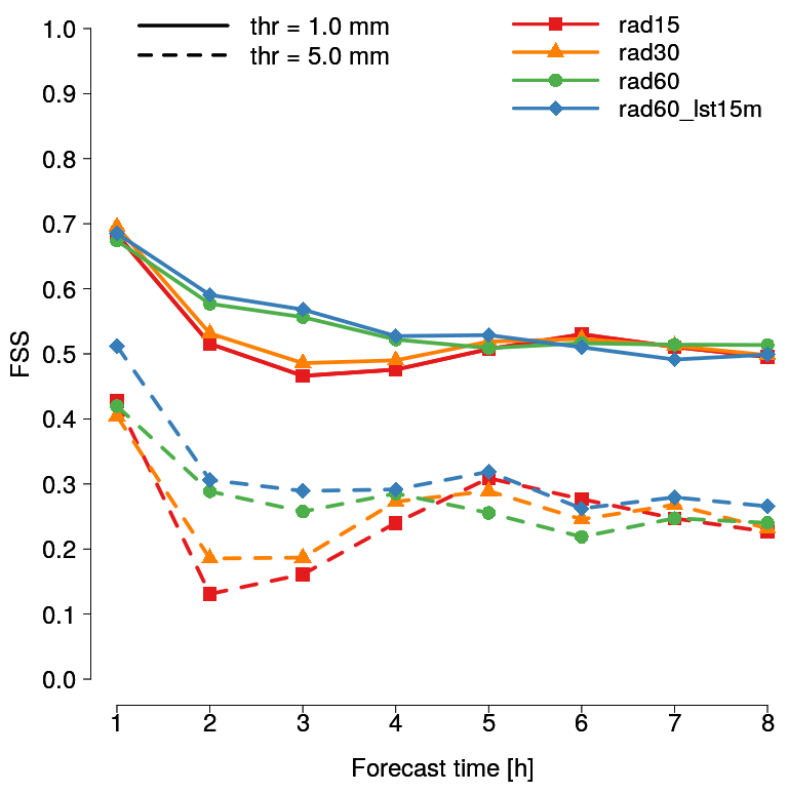

Figure 8. As in Fig. 6 but considering experiments rad15 (red), rad30 (orange), rad60 (green) and rad60_lst15 (blue).

current set-up, the use of a sub-hourly window length degrades QPF accuracy, but this is not due to the introduction of imbalances into the analysis. A possible different explanation is that the reduced analysis error associated with rad15 and rad30 compared to rad60 makes the ensemble employed for the LETKF scheme too small to correctly characterize the forecast error, as suggested in Uboldi and Trevisan (2015).

\subsection{Impact of changing the reflectivity observational error}

A set of experiments is performed to investigate the impact of the reflectivity observational error in the assimilation scheme. In addition to the value of $5 \mathrm{dBZ}$ employed so far, which was estimated by applying the diagnostic described in Desroziers et al. (2005) to this case study, two other values of roe are tested: 10 and $0.5 \mathrm{dBZ}$. The former is employed by Bick et al. (2016) for the assimilation of reflectivity volumes from the German radar network using KENDA and COSMO and, therefore, should be reasonable also for the present study. The latter is a deliberately extreme value that may be chosen in the case of great confidence in the quality of radar observations. These two different values of roe are used in assimilation cycles of $60 \mathrm{~min}$ (rad60_roe 0.5 and rad60_roe 10) and $15 \mathrm{~min}$ (rad15_roe0.5 and rad15_roe 10 ). Therefore, they can be compared with the experiments with our standard value of roe $=5 \mathrm{dBZ}$, respectively rad60 and rad15.

Results of QPF verification in terms of SAL and FSS are reported, respectively, in Figs. 10 and 11. Regarding the experiments with a $60 \mathrm{~min}$ assimilation cycle, SAL verification

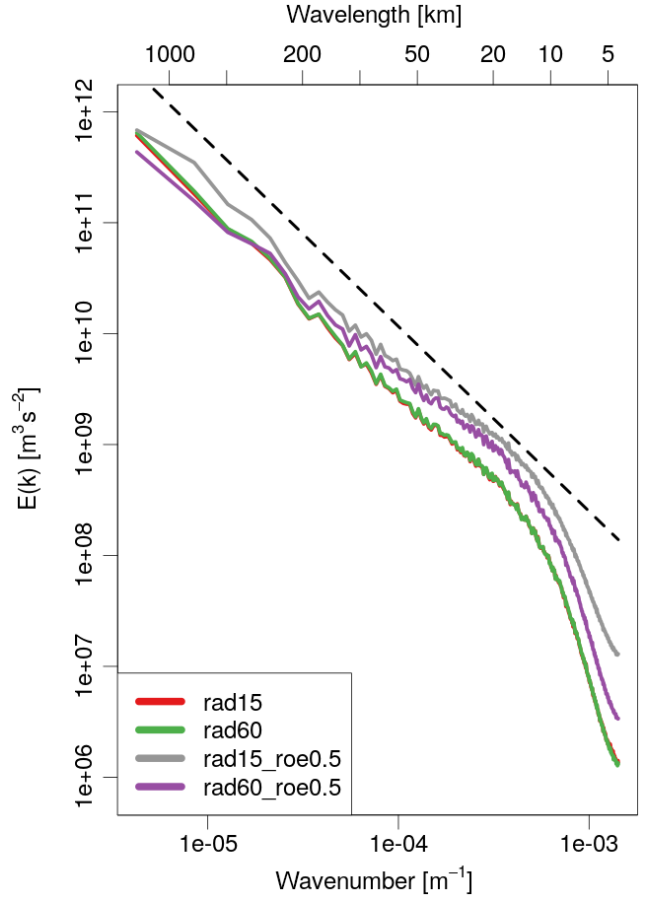

Figure 9. Kinetic energy (KE) spectra computed following the method described by Errico (1985). Each curve is obtained by averaging KE spectra with a frequency of $1 \mathrm{~h}$ during the assimilation procedure and employing analysis values of $u, v$ and $w$ over the whole model domain. The spectra are displayed for experiments rad15 (red), rad60 (green), rad15_roe0.5 (grey) and rad60_roe0.5 (violet). The dashed black line represents a function with a dependence on the wavenumber equal to $-5 / 3$.

(left panel) reveals that rad60_roe0.5 slightly reduces structure and amplitude errors on QPF at lead time $+1 \mathrm{~h}$ compared to $\mathrm{rad} 60$, but the location error is very slightly increased. From +2 to $+4 \mathrm{~h}$, rad60_roe 0.5 has a larger error in all components, except $S$ at +2 and $+3 \mathrm{~h}$. In particular, the $A$ component is remarkably worsened at $+4 \mathrm{~h}$ and the $L$ component at +2 and $+3 \mathrm{~h}$. As observed for the previous experiments, from $+5 \mathrm{~h}$ onwards the results become mixed. When comparing rad60_roe10 to rad60, differences are small and mixed in the whole forecast range. The FSS verification carried out over the whole country of Italy substantially confirms what is observed with SAL: rad60_roe0.5 worsens QPF accuracy from +2 to $+4 \mathrm{~h}$ and the differences compared to rad 60 are even enhanced and extended to $+1 \mathrm{~h}$ when the $5 \mathrm{~mm}$ threshold is considered, and, at the same time, the impact of using a value of roe equal to $10 \mathrm{dBZ}$ instead of $5 \mathrm{dBZ}$ as a neutral impact over the whole forecast range.

With regards to $15 \mathrm{~min}$ assimilation cycles, rad15_roe 0.5 dramatically worsens QPF accuracy over northern Italy in terms of structure (right panel in Fig. 10) up to +5 and up to $+12 \mathrm{~h}$ in terms of amplitude and location (the range between +9 and $+12 \mathrm{~h}$ is not shown). In this regard, the verification of individual forecasts (not shown here) reveals that 

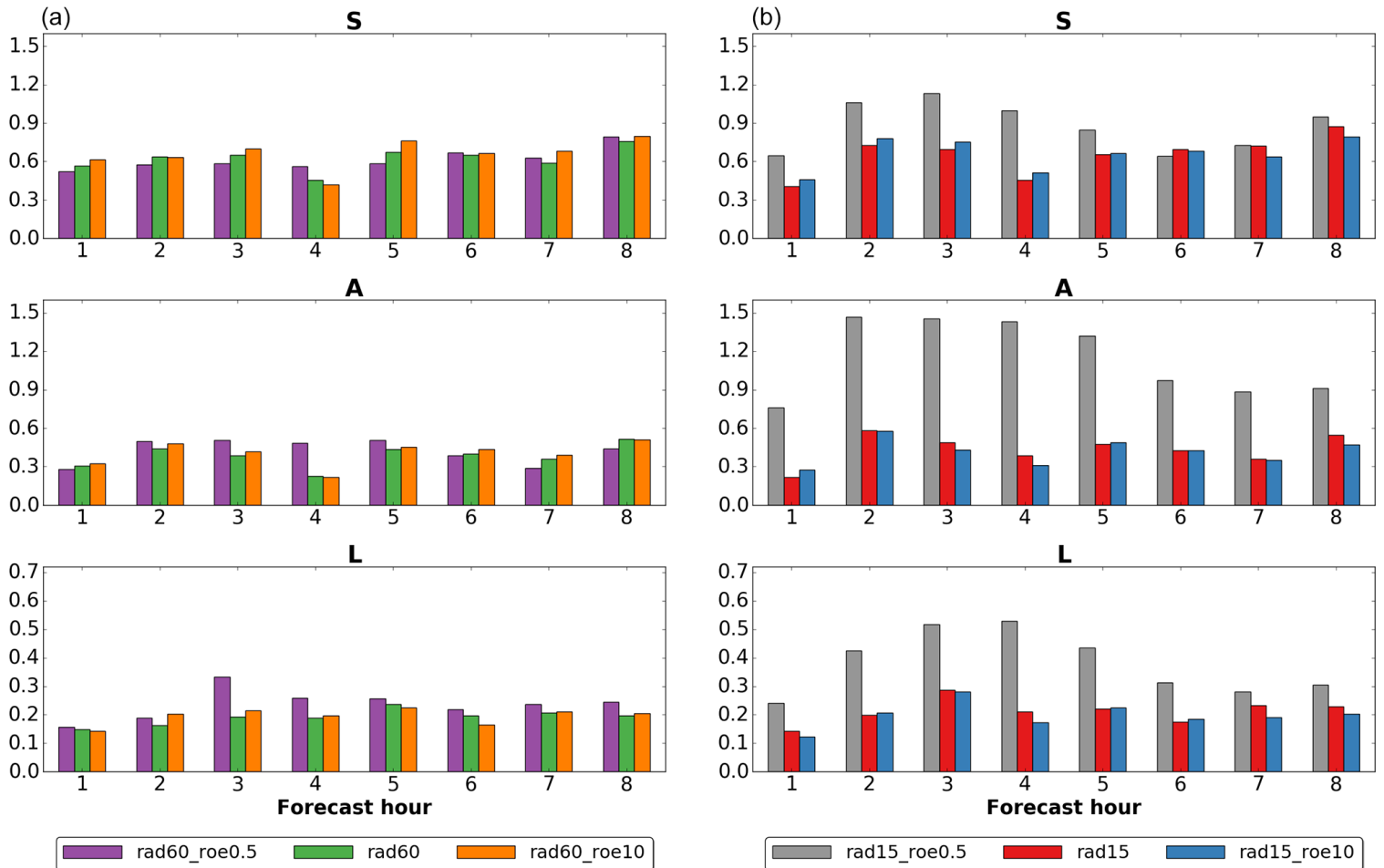

Figure 10. As in Fig. 5 but considering (a) experiments rad60_roe0.5 (violet), rad60 (green) and rad60_roe10 (orange), and (b) experiments rad15_roe0.5 (grey), rad15 (red) and rad15_roe0.5 (blue).
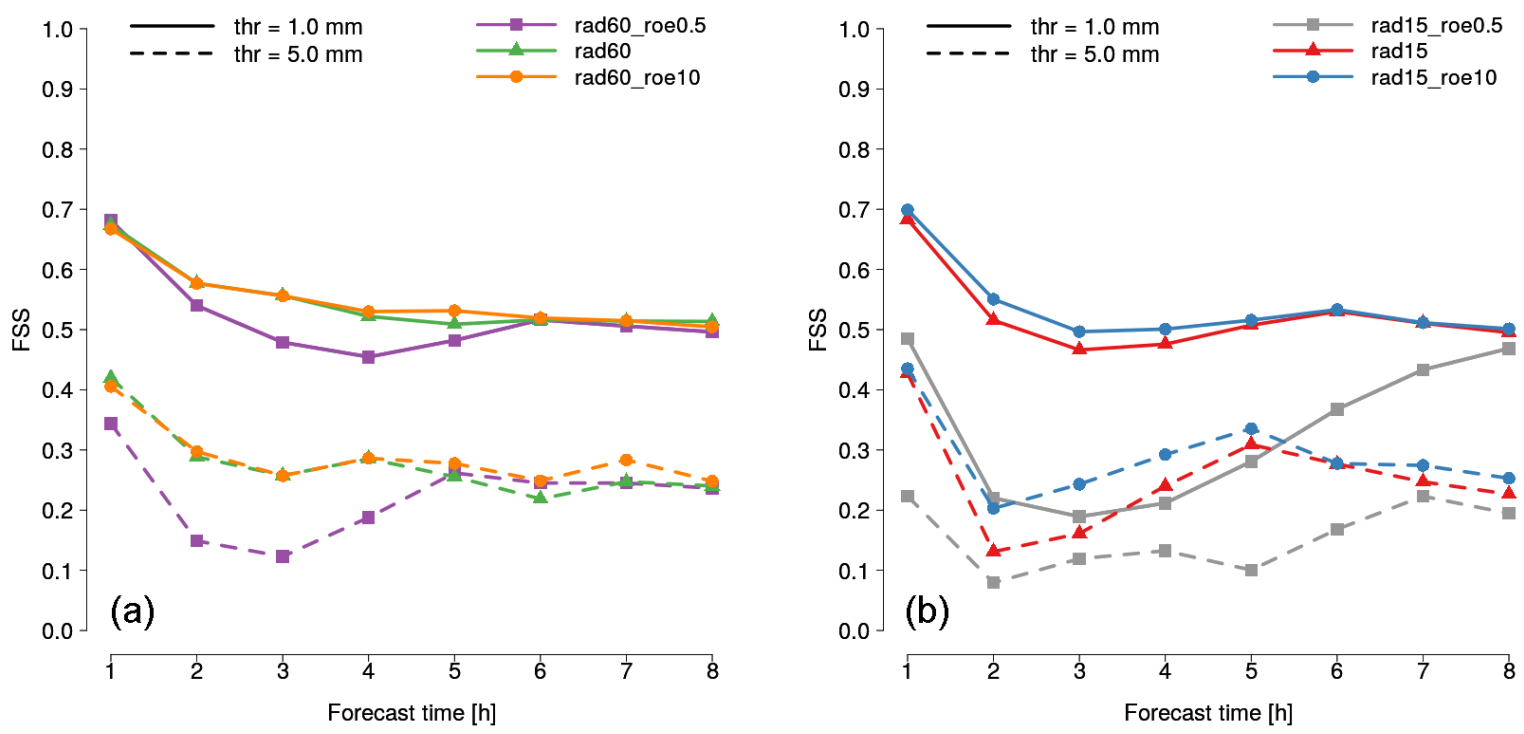

Figure 11. As in Fig. 6 but considering (a) experiments rad60_roe0.5 (violet), rad60 (green) and rad60_roe10 (orange), and (b) experiments rad15_roe0.5 (grey), rad15 (red) and rad15_roe0.5 (blue).

the large error in the $A$ component is due to a systematic underestimation of the average precipitation over the domain. This marked worsening can be appreciated also with FSS verification (right panel in Fig. 11), especially for the $1 \mathrm{~mm}$ threshold. When comparing results of SAL verification for rad15_roe10 and rad15, differences are small and mixed over the whole forecast range. However, in this case, FSS reveals that the former slightly outperforms the latter between +2 and $+4 \mathrm{~h}$ when the $1 \mathrm{~mm}$ threshold is considered, and this is enhanced when considering the $5 \mathrm{~mm}$ threshold. 

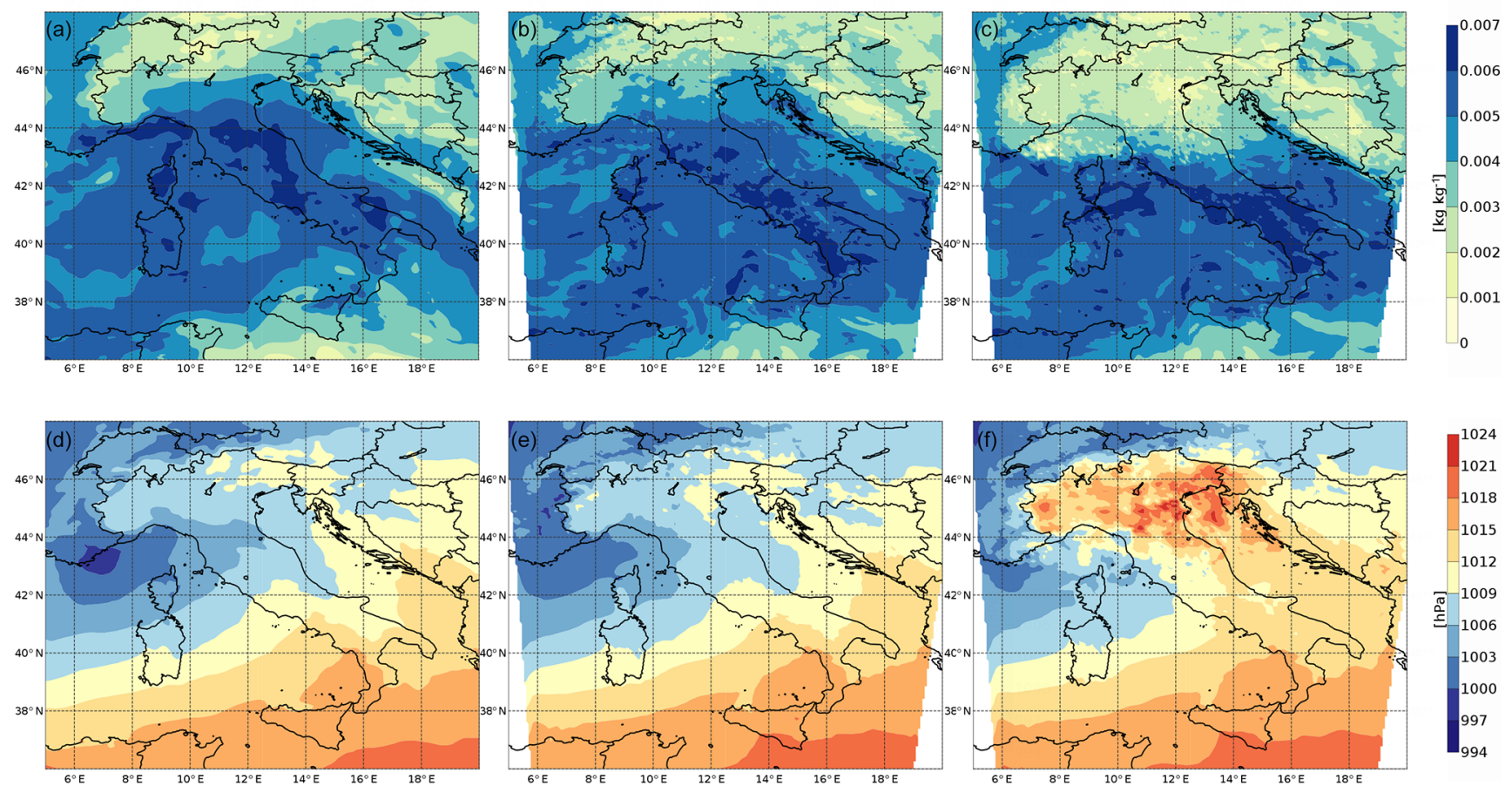

Figure 12. Mean sea level pressure (a-c) and specific humidity at $850 \mathrm{hPa}(\mathbf{d}-\mathbf{f})$ analysis on 5 February at 12:00 UTC for IFS (a, d) rad60 (b, e) and rad15_roe0.5 (c, f).

The overall poor quality of rad15_roe0.5 forecasts is the direct consequence of the poor quality of the analyses from which they are initialized. As an example, in Fig. 12 the mean sea level pressure (MSLP) and specific humidity at $850 \mathrm{hPa}$ of rad15_roe0.5 (right column) analysis on 5 February at 12:00 UTC are shown and compared with the same quantities for the analysis of rad15 (central column) and the Integrated Forecasting System (IFS) of ECMWF (left column). Slight variations can be observed between IFS and rad15 analyses and it seems reasonable that they may simply arise from differences between models and assimilation systems. Conversely, rad15_roe 0.5 analysis exhibits a noticeable increase in MSLP and a decrease in specific humidity over northern Italy. This is in agreement with the decrease in forecast precipitation previously described.

In the same way as described in Sect. 4.2, KE spectra are computed for rad15_roe0.5 and rad60_roe0.5 and displayed in Fig. 9. In both cases, at the smallest wavelength the KE is significantly greater that that of $\mathrm{rad} 15$ or $\mathrm{rad} 60$, and this is particularly evident for rad15_roe0.5. This behavior is indicative of the presence of some undesired noise at small scales (Skamarock, 2004). Therefore, employing a value of roe equal to $0.5 \mathrm{dBZ}$, the assimilation system is not able to correctly remove small-scale noise, especially when really short cycles are employed. Furthermore, the excess of energy associated with the highest wavenumber modes propagates to the larger scales and the slope of the curves at wavelengths greater than $15 \mathrm{~km}$ differs from $-5 / 3$.

\section{Conclusions}

The assimilation of radar data in an operational set-up is a challenging issue. Most of the previous studies are devoted to the assimilation of rainfall estimated from radar data, and they are currently widely employed in meteorological centres all over the world. The continuous increase in computer resources now allows one to directly assimilate reflectivity volumes, but few studies have been dedicated to testing the assimilation of these observations in an operational context. In the present work, the assimilation of reflectivity volumes using the LETKF scheme developed for the high-resolution COSMO model is evaluated. A case study of 4 days in February 2017 is carried out using data from four radars over northern Italy. The quality of the analyses generated by the data assimilation system is assessed in terms of the accuracy of QPF which is verified using SAL (approximately in the region where reflectivity volumes are assimilated) and FSS (over the whole country of Italy).

The assimilation of both conventional data and radar reflectivity volumes in combination with LHN (rad60) improves QPF accuracy compared to our operational set-up (conv60), in which only conventional data are employed together with LHN, and to conv60_nolhn, in which conventional observations are assimilated without performing LHN. The improvement compared to conv60 is remarkable between lead times +2 and $+4 \mathrm{~h}$ and observed with both SAL and FSS. Regarding the comparison with conv60_nolhn, the 
improvement is consistent at $+1 \mathrm{~h}$ and holds (attenuated) up to $+4 \mathrm{~h}$ over northern Italy, while it becomes irrelevant over Italy from lead time $+3 \mathrm{~h}$. Similar improvements are observed when both conventional data and reflectivity volumes are assimilated without LHN (rad60_nolhn), suggesting that the combined use of radar volumes and SRI, not rigorous from a theoretical point of view, does not degrade the results. This can be due to the different nature of the observed values: in case of reflectivity volumes the measure is direct, while for SRI the field is indirectly calculated using an empiric relationship between reflectivity and rain rate. Furthermore, the assimilation schemes also differ dramatically.

In this context, the assimilation of observations collected only in the last $15 \mathrm{~min}$ of each assimilation cycle (rad60_lst15) further slightly enhances the positive impact of assimilating reflectivity volumes. This result is observed when considering precipitation more intense than $5 \mathrm{~mm} \mathrm{~h}^{-1}$, while the impact of using rad60_lst 15 instead of rad60 analyses is neutral when a $1 \mathrm{~mm}$ threshold is employed. Taking into account that this configuration also reduces the computational cost associated with the assimilation of radar data, it seems to be the most promising for an operational implementation. However, further tests would be necessary to evaluate whether the same conclusion arises when only observations at the analysis time are assimilated. Regarding the length of assimilation cycles, the shortening of their length to 30 and 15 min slightly improves QPF accuracy at lead time $+1 \mathrm{~h}$ over the region where they are assimilated, but worsens results between lead times +2 and $+4 \mathrm{~h}$, both over northern Italy and in the rest of the country. This is not due to the introduction of imbalances in the analyses. A possible explanation, which needs further investigation, is that the more frequent assimilation reduces the analysis error, potentially making the ensemble spread too small to properly characterize the forecast error (Uboldi and Trevisan, 2015).

With regards to the observational error, it is found that a value of roe equal to $0.5 \mathrm{dBZ}$ negatively affects the quality of the analyses and of the subsequent forecasts, because the model is not able to remove noise at the smallest scales. This leads to large errors in all prognostic fields in the area where radar data are assimilated and, as a consequence, to a very poor quality of the forecasts. This is particularly significant when $15 \mathrm{~min}$ assimilation cycles are employed, in which case forecast precipitation is strongly underestimated and misplaced. Conversely, a value of $10 \mathrm{dBZ}$, that is, a value which is twice that estimated using Desroziers statistics, leads to similar results obtained with roe $=5 \mathrm{dBZ}$, but slightly improves QPF accuracy when 15 min cycles are employed.

The observed improvement in QPF accuracy associated with the assimilation of reflectivity volumes is promising, even if it is limited to only the first few hours of forecast. Other tests are necessary to validate whether this improvement holds in other synoptic conditions and for longer case studies. Furthermore, several tests need to be performed to extend the impact of the assimilation beyond the first few hours of forecast. In particular, the value of the reflectivity observational error seems to have a strong impact on QPF accuracy. Therefore, it seems reasonable that a further improvement can be achieved when roe is made dependent on the range, elevation, radar station and meteorological condition, but a better comprehension and estimation of this value is mandatory before testing more complex configurations.

Data availability. The data underlying this research are not publicly available, since they belong to Arpae Emilia-Romagna (simulations, radar data for the Emilia-Romagna region), Arpa Piemonte (radar data for the Piemonte region) and the Dipartimento of Protezione Civile (raingauges, data for LHN and verification). However, they can be obtained from Arpae Emilia-Romagna upon request by email to the corresponding author.

Author contributions. CM designed the experiments. TG and VP carried them out, performing simulations and validation. The manuscript was mainly written by TG and revised by VP and CM. The whole project was under the supervision of TP and PPA.

Competing interests. The authors declare that they have no conflict of interest.

Special issue statement. This article is part of the special issue "Numerical modeling, predictability and data assimilation in weather, ocean and climate: A special issue honoring the legacy of Anna Trevisan (1946-2016)". It is a result of the Symposium Honoring the Legacy of Anna Trevisan - Bologna, Italy, 17-20 October 2017

Acknowledgements. This work was carried out within the framework of the Cooperation Agreement with the Presidency of the Council of Ministers and the Department of Civil Protection, for the development of knowledge, methodologies and technologies useful for the implementation, at the functional centers, of national monitoring, forecasting and surveillance systems. We would like to thank Roberto Cremonini for providing reflectivity volumes of the radars of the Liguria and Piemonte regions and Anna Fornasiero for the correction of radar rainfall fields with rain gauges. Finally, we thank the reviewers and the editor Alberto Carrassi for the numerous and valuable suggestions that helped us to improve the manuscript.

Edited by: Alberto Carrassi

Reviewed by: two anonymous referees

\section{References}

Anderson, J. L.: Spatially and temporally varying adaptive covariance inflation for ensemble filters, Tellus A, 61, 72-83, https://doi.org/10.1111/j.1600-0870.2008.00361.x, 2009. 
Anderson, J. L. and Anderson, S. L.: A Monte Carlo Implementation of the Nonlinear Filtering Problem to Produce Ensemble Assimilations and Forecasts, Mon. Weather Rev., 127, 2741-2758, https://doi.org/10.1175/15200493(1999)127<2741:AMCIOT>2.0.CO;2, 1999.

Baldauf, M., Seifert, A., Förstner, J., Majewski, D., Raschendorfer, M., and Reinhardt, T.: Operational Convective-Scale Numerical Weather Prediction with the COSMO Model: Description and Sensitivities, Mon. Weather Rev., 139, 3887-3905, https://doi.org/10.1175/MWR-D-10-05013.1, 2011.

Bannister, R. N.: A review of operational methods of variational and ensemble-variational data assimilation, Q. J. Roy. Meteor. Soc., 143, 607-633, https://doi.org/10.1002/qj.2982, 2016.

Berner, J., Fossell, K. R., Ha, S.-Y., Hacker, J. P., and Snyder, C.: Increasing the Skill of Probabilistic Forecasts: Understanding Performance Improvements from ModelError Representations, Mon. Weather Rev., 143, 1295-1320, https://doi.org/10.1175/MWR-D-14-00091.1, 2015.

Bick, T., Simmer, C., Trömel, S., Wapler, K., Hendricks Franssen, H.-J., Stephan, K., Blahak, U., Schraff, C., Reich, H., Zeng, Y., and Potthast, R.: Assimilation of 3D radar reflectivities with an ensemble Kalman filter on the convective scale, Q. J. Roy. Meteor. Soc., 142, 1490-1504, https://doi.org/10.1002/qj.2751, 2016.

Bonavita, M., Torrisi, L., and Marcucci, F.: Ensemble data assimilation with the CNMCA regional forecasting system, Q. J. Roy. Meteor. Soc., 136, 132-145, https://doi.org/10.1002/qj.553, 2010.

Buehner, M., Houtekamer, P. L., Charette, C., Mitchell, H. L., and $\mathrm{He}, \mathrm{B}$. : Intercomparison of Variational Data Assimilation and the Ensemble Kalman Filter for Global Deterministic NWP. Part I: Description and Single-Observation Experiments, Mon. Weather Rev., 138, 1550-1566, https://doi.org/10.1175/2009MWR3157.1, 2010a.

Buehner, M., Houtekamer, P. L., Charette, C., Mitchell, H. L., and He, B.: Intercomparison of Variational Data Assimilation and the Ensemble Kalman Filter for Global Deterministic NWP. Part II: One-Month Experiments with Real Observations, Mon. Weather Rev., 138, 1567-1586, https://doi.org/10.1175/2009MWR3158.1, 2010b.

Clark, P., Roberts, N., Lean, H., Ballard, S. P., and CharltonPerez, C.: Convection-permitting models: a step-change in rainfall forecasting, Meteorol. Appl., 23, 165-181, https://doi.org/10.1002/met.1538, 2016.

Courtier, P., Andersson, F., Hackley, W., Vasiljevic, D., Hamrud, M., Hollingsworth, A., Rabier, F., Fisher, M., and Pailleux, J.: The ECMWF implementation of three dimensional variational assimilation (3D-Var). I: Formulation, Q. J. Roy. Meteor. Soc., 124, 1783-1807, https://doi.org/10.1002/qj.49712455002, 1998.

Cuo, L., Pagano, T. C., and Wang, Q. J.: A Review of Quantitative Precipitation Forecasts and Their Use in Short- to MediumRange Streamflow Forecasting, J. Hydrometeorol., 12, 713-728, 2011.

Davolio, S., Silvestro, F., and Gastaldo, T.: Impact of Rainfall Assimilation on High-Resolution Hydrometeorological Forecasts over Liguria, Italy, J. Hydrometeorol., 18, 2659-2680, https://doi.org/10.1175/JHM-D-17-0073.1, 2017.

Desroziers, G., Berre, L., Chapnik, B., and Poli, P.: Diagnosis of observation, background and analysis-error statistics in observation space, Q. J. Roy. Meteor. Soc., 131, 3385-3396, https://doi.org/10.1256/qj.05.108, 2005.

Dixon, M., Li, Z., Lean, H., Roberts, N., and Ballard, S.: Impact of Data Assimilation on Forecasting Convection over the United Kingdom Using a High-Resolution Version of the Met Office Unified Model, Mon. Weather Rev., 137, 1562-1584, https://doi.org/10.1175/2008MWR2561.1, 2009.

Doms, G., Förstner, J., Heise, E., Herzog, H.-J., Mironov, D., Raschendorfer, M., Reinhardt, T., Ritter, B., Schrodin, R., Schulz, J.-P., and Vogel, G.: A Description of the Nonhydrostatic Regional COSMO Model, Part II: Physical Parameterization, Tech. rep., available at: http://www.cosmo-model.org/content/ model/documentation/core/default.htm (last access: 2 November 2018), 2011.

Errico, R. M.: Spectra Computed from a Limited Area Grid, Mon. Weather Rev., 113, 1554-1562, https://doi.org/10.1175/15200493(1985)113<1554:SCFALA>2.0.CO;2, 1985.

Evensen, G.: Sequential data assimilation with a nonlinear quasigeostrophic model using Monte Carlo methods to forecast error statistics, J. Geophys. Res, 99, 10143-10162, 1994.

Ferting, E. J., Harlim, J., and Hunt, B. R.: A comparative study of 4D-VAR and a 4D Ensemble Kalman Filter: perfect model simulations with Lorenz-96, Tellus A, 59, 96-100, https://doi.org/10.1111/j.1600-0870.2006.00205.x, 2007.

Gaspari, G. and Cohn, S. E.: Construction of correlation functions in two and three dimensions, Q. J. Roy. Meteor. Soc., 125, 723757, https://doi.org/10.1002/qj.49712555417, 1999.

Gustafsson, N. and Bojarova, J.: Four-dimensional ensemble variational (4D-En-Var) data assimilation for the HIgh Resolution Limited Area Model (HIRLAM), Nonlin. Processes Geophys., 21, 745-762, https://doi.org/10.5194/npg-21-745-2014, 2014.

Hamrud, M., Bonavita, M., and Isaksen, L.: EnKF and Hybrid Gain Ensemble Data Assimilation. Part I: EnKF Implementation, Mon. Weather Rev., 143, 4847-4864, https://doi.org/10.1175/MWR-D-14-00333.1, 2015.

Harnisch, F. and Keil, C.: Initial Conditions for ConvectiveScale Ensemble Forecasting Provided by Ensemble Data Assimilation, Mon. Weather Rev., 143, 1583-1600, https://doi.org/10.1175/MWR-D-14-00209.1, 2015.

Houtekamer, P. L. and Mitchell, H. L.: Data Assimilation Using an Ensemble Kalman Filter Technique, Mon. Weather Rev., 126, 796-811, https://doi.org/10.1175/15200493(1998)126<0796:DAUAEK>2.0.CO;2, 1998.

Houtekamer, P. L. and Mitchell, H. L.: Ensemble Kalman filtering, Q. J. Roy. Meteor. Soc., 131, 3269-3289, https://doi.org/10.1256/qj.05.135, 2005.

Houtekamer, P. L. and Zhang, F.: Review of the Ensemble Kalman Filter for Atmospheric Data Assimilation, Mon. Weather Rev., 144, 4489-4532, https://doi.org/10.1175/MWRD-15-0440.1, 2016.

Houtekamer, P. L., Mitchell, H. L., Pellerin, G., Buehner, M., Charron, M., Spacek, L., and Hansen, B.: Atmospheric Data Assimilation with an Ensemble Kalman Filter: Results with Real Observations, Mon. Weather Rev., 133, 604-620, https://doi.org/10.1175/MWR-2864.1, 2005.

Hunt, B. R., Kostelich, E. J., and Szunyogh, I.: Efficient data assimilation for spatiotemporal chaos: A local ensemble transform Kalman filter, Physica D, 230, 112-126, https://doi.org/10.1016/j.physd.2006.11.008, 2007. 
Janjić, T., Bormann, N., Bocquet, M., Carton, J. A., Cohn, S. E., Dance, S. L., Losa, S. N., Nichols, N. K., Potthast, R., Waller, J. A., and Weston, P.: On the representation error in data assimilation, Q. J. Roy. Meteor. Soc., 144, 1257-1278, https://doi.org/10.1002/qj.3130, 2017.

Jones, C. D. and Macpherson, B.: A latent heat nudging scheme for the assimilation of precipitation data into an operational mesoscale model, Meteorol. Appl., 4, 269-277, https://doi.org/10.1017/S1350482797000522, 2006.

Koistinen, J. and Puhakka, T.: An improved spatial gauge-radar adjustment technique, in: Proc. 20th Conference on Radar Meteorology, 1981, Boston, USA, AMS, 179-186, 1981.

Leuenberger, D. and Rossa, A.: Revisiting the latent heat nudging scheme for the rainfall assimilation in convective system, in: Proc. of 3rd European Radar Conference on Radar Meteorology and Hydrology (ERAD), Visby, Gotland, Sweden, 6-10 September 2004, 162-167, 2004.

Leuenberger, D. and Rossa, A.: Revisiting the latent heat nudging scheme for the rainfall assimilation of a simulated convective storm, Meteorol. Atmos. Phys., 98, 195-215, 2007.

Lin, Y.-L., Farley, R. D., and Orville, H. D.: Bulk Parameterization of the Snow Field in a Cloud Model, J. Clim. Appl. Meteorol., 22, 1065-1092, https://doi.org/10.1175/15200450(1983)022<1065:BPOTSF>2.0.CO;2, 1983.

Meng, Z. and Zhang, F.: Limited-Area Ensemble-Based Data Assimilation, Mon. Weather Rev., 139, 2025-2045, https://doi.org/10.1175/2011MWR3418.1, 2011.

Michelson, D. B.: Quality control of weather radar data for quantitative application, $\mathrm{PhD}$ thesis, Telford Institute of Environmental Systems, University of Salford, UK, 286 pp., 2003.

Mitchell, H. L. and Houtekamer, P. L.: An Adaptive Ensemble Kalman Filter, Mon. Weather Rev., 128, 416-433, https://doi.org/10.1175/15200493(2000)128<0416:AAEKF>2.0.CO;2, 2000.

Miyoshi, T., Sato, Y., and Kadowaki, T.: Ensemble Kalman Filter and 4D-Var Intercomparison with the Japanese Operational Global Analysis and Prediction System, Mon. Weather Rev., 138, 2846-2866, https://doi.org/10.1175/2010MWR3209.1, 2010.

Nastrom, G. D. and Gage, K. S.: A Climatology of Atmospheric Wavenumber Spectra of Wind and Temperature Observed by Commercial Aircraft, J. Atmos. Sci., 42, 950-960, https://doi.org/10.1175/15200469(1985)042<0950:ACOAWS>2.0.CO;2, 1985.

Poterjoy, J.: A Localized Particle Filter for High-Dimensional Nonlinear Systems, Mon. Weather Rev., 144, 59-76, https://doi.org/10.1175/MWR-D-15-0163.1, 2016.

Raschendorfer, M.: The new turbulence parametrization of LM, COSMO newsletter, 1, 89-97, 2001.

Rinollo, A., Vulpiani, G., Puca, S., Pagliara, P., Kaňák, J., Lábó, E., Okon, L'., Roulin, E., Baguis, P., Cattani, E., Laviola, S., and Levizzani, V.: Definition and impact of a quality index for radar-based reference measurements in the H-SAF precipitation product validation, Nat. Hazards Earth Syst. Sci., 13, 2695-2705, https://doi.org/10.5194/nhess-13-2695-2013, 2013.

Ritter, B. and Geleyn, J.-F.: A Comprehensive Radiation Scheme for Numerical Weather Prediction Models with Potential Applications in Climate Simulations, Mon. Weather Rev., 120, 303-325, https://doi.org/10.1175/15200493(1992)120<0303:ACRSFN>2.0.CO;2, 1992.
Roberts, N. M. and Lean, H. W.: Scale-Selective Verification of Rainfall Accumulations from High-Resolution Forecasts of Convective Events, Mon. Weather Rev., 136, 78-97, https://doi.org/10.1175/2007MWR2123.1, 2008.

Röpnack, A., Hense, A., Gebhardt, C., and Majewski, D.: Bayesian Model Verification of NWP Ensemble Forecasts, Mon. Weather Rev., 141, 375-387, https://doi.org/10.1175/MWR-D11-00350.1, 2013.

Rossa, A., Nurmi, P., and Ebert, E.: Overview of methods for the verification of quantitative precipitation forecasts, Springer Berlin Heidelberg, 419-452, https://doi.org/10.1007/978-3-54077655-0_16, 2008.

Schraff, C., Reich, H., Rhodin, A., Schomburg, A., Stephan, K., Periáñez, A., and Potthast, R.: Kilometre-scale ensemble data assimilation for the COSMO model (KENDA), Q. J. Roy. Meteor. Soc., 142, 1453-1472, https://doi.org/10.1002/qj.2748, 2016.

Seifert, A. and Beheng, K. D.: A double-moment parameterization for simulating autoconversion, accretion and selfcollection, Atmos. Res., 59-60, 265-281, https://doi.org/10.1016/S01698095(01)00126-0, 2001.

Skamarock, W. C.: Evaluating Mesoscale NWP Models Using Kinetic Energy Spectra, Mon. Weather Rev., 132, 3019-3032, https://doi.org/10.1175/MWR2830.1, 2004.

Snyder, C. and Zhang, F.: Assimilation of Simulated Doppler Radar Observations with an Ensemble Kalman Filter, Mon. Weather Rev., 131, 1663-1677, https://doi.org/10.1175//2555.1, 2003.

Sokol, Z.: Effects of an assimilation of radar and satellite data on a very-short range forecast of heavy convective rainfalls, Atmos. Res., 93, 188-206, https://doi.org/10.1016/j.atmosres.2008.11.001, 2009.

Stephan, K., Klink, S., and Schraff, C.: Assimilation of radarderived rain rates into the convective-scale model COSMODE at DWD, Q. J. Roy. Meteor. Soc., 134, 1315-1326, https://doi.org/10.1002/qj.269, 2008.

Tiedtke, M.: A Comprehensive Mass Flux Scheme for $\mathrm{Cu}-$ mulus Parameterization in Large-Scale Models, Mon. Weather Rev., 117, 1779-1800, https://doi.org/10.1175/15200493(1989)117<1779:ACMFSF>2.0.CO;2, 1989.

Tong, M. and Xue, M.: Ensemble Kalman Filter Assimilation of Doppler Radar Data with a Compressible Nonhydrostatic Model: OSS Experiments, Mon. Weather Rev., 133, 1789-1807, https://doi.org/10.1175/MWR2898.1, 2005.

Uboldi, F. and Trevisan, A.: Multiple-scale error growth in a convection-resolving model, Nonlin. Processes Geophys., 22, 113, https://doi.org/10.5194/npg-22-1-2015, 2015.

van Leeuwen, P. J.: Particle Filtering in Geophysical Systems, Mon. Weather Rev., 137, 4089-4114, https://doi.org/10.1175/2009MWR2835.1, 2009.

Wang, X., Barker, D. M., Snyder, C., and Hamill, T. M.: A Hybrid ETKF-3DVAR Data Assimilation Scheme for the WRF Model. Part I: Observing System Simulation Experiment, Mon. Weather Rev., 136, 5116-5131, https://doi.org/10.1175/2008MWR2444.1, 2008.

Wernli, H., Paulat, M., Hagen, M., and Frei, C.: SAL - A Novel Quality Measure for the Verification of Quantitative Precipitation Forecasts, Mon. Weather Rev., 136, 4470-4487, https://doi.org/10.1175/2008MWR2415.1, 2008.

Wernli, H., Hofmann, C., and Zimmer, M.: Spatial Forecast Verification Methods Intercomparison Project: Applica- 
tion of the SAL Technique, Weather Forecast., 24, 1472-1484, https://doi.org/10.1175/2009WAF2222271.1, 2009.

Yang, S.-C., Kalnay, E., Hunt, B., and Neill, E. B.: Weight interpolation for efficient data assimilation with the Local Ensemble Transform Kalman Filter, Q. J. Roy. Meteor. Soc., 135, 251-262, https://doi.org/10.1002/qj.353, 2009.

Yano, J.-I., Ziemiański, M. Z., Cullen, M., Termonia, P., Onvlee, J., Bengtsson, L., Carrassi, A., Davy, R., Deluca, A., Gray, S. L., Homar, V., Köhler, M., Krichak, S., Michaelides, S., Phillips, V. T. J., Soares, P. M. M., and Wyszogrodzki, A. A.: Scientific Challenges of Convective-Scale Numerical Weather Prediction, B. Am. Meteorol. Soc., 99, 699-710, https://doi.org/10.1175/BAMS-D-17-0125.1, 2018.
Zhang, F., Snyder, C., and Sun, J.: Impacts of Initial Estimate and Observation Availability on Convective-Scale Data Assimilation with an Ensemble Kalman Filter, Mon. Weather Rev., 132, 1238-1253, https://doi.org/10.1175/15200493(2004)132<1238:IOIEAO>2.0.CO;2, 2004. 